\title{
Intermobility of barium, strontium, and lead in chloride and sulfate leach solutions
}

\author{
Mark Rollog ${ }^{1 *}$, Nigel J. Cook ${ }^{1}$, Paul Guagliardo², Kathy Ehrig ${ }^{3}$, Sarah E. Gilbert ${ }^{4}$ and Matt Kilburn²
}

\begin{abstract}
Production of radionuclide-free copper concentrates is dependent on understanding and controlling the deportment of daughter radionuclides (RNs) produced from ${ }^{238} \mathrm{U}$ decay, specifically ${ }^{226} \mathrm{Ra},{ }^{210} \mathrm{~Pb}$, and ${ }^{210} \mathrm{Po}$. Sulfuric acid leaching is currently employed in the Olympic Dam processing plant (South Australia) to remove $U$ and fluorine from copper concentrates prior to smelting but does not adequately remove the aforementioned RN. Due to chemical similarities between lead and alkaline earth metals (including Ra), two sets of experiments were designed to understand solution interactions between $\mathrm{Sr}, \mathrm{Ba}$, and $\mathrm{Pb}$ at various conditions. Nanoscale secondary ion mass spectrometry (NanoSIMS) isotopic spatial distribution maps and laser ablation inductively coupled-plasma mass spectrometry transects were performed on laboratory-grown crystals of baryte, celestite, and anglesite which had been exposed to different solutions under different $\mathrm{pH}$ and reaction time conditions. Analysis of experimental products reveals three uptake mechanisms: overgrowth of nearly pure $\mathrm{SrSO}_{4}$ and $\mathrm{PbSO}_{4}$ on baryte; incorporation of minor of $\mathrm{Pb}$ and $\mathrm{Ba}$ into celestite due to diffusion; and extensive replacement of $\mathrm{Pb}$ by $\mathrm{Sr}$ (and less extensive replacement of $\mathrm{Pb}$ by $\mathrm{Ba}$ ) in anglesite via coupled dissolution-reprecipitation reactions. The presence of $\mathrm{H}_{2} \mathrm{SO}_{4}$ either enhanced or inhibited these reactions. Kinetic modelling supports the experimental results, showing potential for extrapolating the $\left(\mathrm{Sr}, \mathrm{Ba}\right.$, $\mathrm{Pb}_{\mathrm{Sb}} \mathrm{SO}_{4}$ system to encompass $\mathrm{RaSO}_{4}$. Direct observation of grain-scale element distributions by nanoSIMS aids understanding of the controlling conditions and mechanisms of replacement that may be critical steps for $\mathrm{Pb}$ and Ra removal from concentrates by allowing construction of a cationic replacement scenario targeting $\mathrm{Pb}$ or Ra, or ideally all insoluble sulfates. Experimental results provide a foundation for further investigation of RN uptake during minerals processing, especially during acid leaching. The new evidence enhances understanding of micro- to nanoscale chemical interactions and not only aids determination of where radionuclides reside during each processing stage but also guides development of flowsheets targeting their removal.
\end{abstract}

Keywords: Alkali earth sulfates, Sulfate leaching, NanoSIMS analysis, Cation intermobility, Radionuclides

\section{Introduction}

Uranium-bearing mineral deposits, such as the Olympic Dam iron oxide-copper-gold-uranium (IOCG-U) orebody, South Australia, contain not only appreciable amounts of uranium and thorium, but also all daughter isotopes produced by radioactive decay. Elimination or reduction of some daughter radionuclides (RNs) during processing represents a unique metallurgical challenge. As examples, ${ }^{226} \mathrm{Ra},{ }^{210} \mathrm{~Pb}$, and ${ }^{210} \mathrm{Po}$ are all found

\footnotetext{
*Correspondence: mark.rollog@adelaide.edu.au

1 School of Chemical Engineering, The University of Adelaide, Adelaide, SA 5005, Australia

Full list of author information is available at the end of the article
}

in Olympic Dam ore feed at sub-ppb concentrations. To achieve activities of $<1 \mathrm{~Bq} / \mathrm{g}$ per radionuclide in the final copper concentrate, concentrations of roughly 27 partsper-trillion (ppt), 370 parts-per-quadrillion (ppq), and 6 ppq, respectively, are required. Since these concentration values fall below the minimum detection limits of most conventional instrumentation for analysis of samples in situ, it is simpler to use proxies, where possible, to predict the behavior of these elements during processing.

Understanding hydrothermal mobility of cations in ore deposits is important for the study of ore genesis, but this information may be of limited usefulness on the processing floor. Hydrometallurgy involving high-temperature leach solutions containing acids, alkalis, complexing 
agents, organic solvents, redox reagents, or more likely a combination of the above, can completely rearrange the chemical composition of ore material-preferentially to the operator's benefit. Sulfuric acid leaching is a key solution currently employed in the Olympic Dam plant to reduce $\mathrm{U}$ and $\mathrm{RNs}$ in copper concentrates prior to smelting (8 to 12 -h leach time at $\sim 60{ }^{\circ} \mathrm{C}$ and $\mathrm{pH}$ of $\sim 1-1.5$ ). A simplified Olympic Dam processing flowsheet is presented in Schmandt et al. [38]. Since the chlorides and nitrates of $\mathrm{Ra}, \mathrm{Po}$, and to some extent $\mathrm{Pb}$, are all waterand acid-soluble, these are not of primary concern. Sulfates of these cations, however, are of great interest due to their insolubility and potential for radionuclide sequestration.

Before attempting to determine the deportment of Ra, Po or ${ }^{210} \mathrm{~Pb}$, it is vital to understand intermobility of $\mathrm{Ba}$, $\mathrm{Sr}$ and $\mathrm{Pb}$ among their insoluble sulfates-the minerals baryte, celestite, and anglesite. A significant amount of work has been done in this field, primarily on individual compounds. Strontium sulfate solubility in water $[16,20,32]$, in chloride solutions $[5,20,32]$, and in sulfate solutions [20] has been determined, as has extraction and biosorption of $\mathrm{Sr}$ in the environment $[14,43]$. Barium sulfate solubility in water $[16,31]$, chloride solutions [4, 5, 7, 31], and sulfate solutions [7] has likewise been covered, notably from researchers interested in boiler scale. Lead sulfate solubility greatly affects leadacid battery performance and has therefore been extensively measured in water [18], and in chloride [21] and sulfate solutions $[17,18,21]$. Radium solubilities have also been determined $[3,44]$. These are but a few of the studies addressing solubilities in the entire $\mathrm{Sr}-\mathrm{Ba}-\mathrm{Pb}-\mathrm{Ra}-$ $\mathrm{Cl}-\mathrm{SO}_{4}-\mathrm{H}^{+}-\mathrm{H}_{2} \mathrm{O}$ system. Current consensus is that solubility of the alkali metal (and lead) sulfates in water at $60{ }^{\circ} \mathrm{C}$ is $\mathrm{Mg}>\mathrm{Ca}>\mathrm{Sr}>\mathrm{Pb}>\mathrm{Ba}>\mathrm{Ra}$. Generally, solubilities positively correlate with chloride activity (through complexation), although $\mathrm{SrSO}_{4}$ solubility reaches a maximum between 2 and $3 \mathrm{~N} \mathrm{NaCl}$ or $\mathrm{HCl}$, decreasing at higher concentrations [20]. This would suggest a simple chloride leach may be a potential approach to removal of selected RNs, but the system is far more complex than it initially appears.

Process waters at Olympic Dam contain chloride (e.g., flotation water is 2.5 to $4 \mathrm{~g} / \mathrm{L} \mathrm{Cl}^{-}$), as does the ore itself, but the sulfuric acid leach process (involving up to $150 \mathrm{~g} / \mathrm{L}$ sulfate) overwhelmingly dictates solution activity and $\mathrm{pH}$. From a RN standpoint, sulfuric acid would be the least favorable reactant due to the insolubility of $\mathrm{RaSO}_{4}$, $\mathrm{PbSO}_{4}$, and $\mathrm{PoSO}_{4}$. Nonetheless, efficiency in removal of fluorine as well as dissolution of most uranium/thorium and rare earth species-coupled with low cost-makes sulfuric acid the logical, practical choice. To that end, optimizing the process already in place is preferential to redesigning the entire system. With additional information about nanoscale mineral-fluid reactions and the behavior of $\mathrm{RN}$-sulfate nanoparticles, it may be possible to modify existing industrial processes to minimize their accumulation in economic products.

To elicit this information, two methods were employed. Laser ablation inductively coupled-plasma mass spectrometry (LA-ICP-MS) is a powerful, well-established tool for generating quantitative compositional data in solids, and is accordingly widely applied across the earth sciences and in mineral processing research [6]. It has, however, several drawbacks. Quadrupole mass spectrometry generally has a mass resolution of 1 atomic mass unit (amu), which prevents distinction between the mass of interest and isobaric mass interferences. Additionally, the finest spatial resolution available is limited by a minimum $3 \mu \mathrm{m}$-diameter spot (commonly resulting in a much larger pit, depending on the mineral). For quantitative trace element analysis, much larger spot sizes are required. The Cameca nanoscale secondary ion mass spectrometry (nanoSIMS) platform is an imaging technique which offers solutions to both the above problems. Each of seven detectors on the nanoSIMS has mass resolution approaching $0.1 \mathrm{amu}$, which is very useful in distinguishing, for example, ${ }^{226} \mathrm{Ra}$ (226.0254) from ${ }^{88} \mathrm{Sr}^{138} \mathrm{Ba}$ (225.811). Additionally, the effective spot size for high concentration elements can be $<100 \mathrm{~nm}$, although for trace elements may approach $700 \mathrm{~nm}$. This still represents a significant improvement over LA-ICP-MS for the resolution of nanoscale features. NanoSIMS, however, is not currently quantifiable - at least not for mineral analyses. Although each is independently limited, the complementary use of both methods provides the quantification and spatial resolution necessary for the results required in this investigation.

Through the combined analyses provided by these two analytical platforms, we strive to better understand the deportment of $\mathrm{Sr}, \mathrm{Ba}, \mathrm{Pb}$, and by extension, also $\mathrm{Ra}$, throughout ore processing at Olympic Dam. Process methods are ever-changing; optimization is achieved via complex formulae based on mineral abundances, elemental compositions, operating costs, and time-weighed against the constantly moving targets of commodity prices. Even slight adjustments in certain mathematical expressions may result in significant benefit to the operators, so it is crucial to understand (to the extent possible and/or realistically implementable) the intimate mechanisms responsible for the behavior of selected elementseither beneficial or detrimental-during processing. Beyond minerals processing, these results provide valuable insight regarding mechanisms involved in natural processes such as ore formation, hydrothermal alteration, and weathering-and anthropogenic processes including 
soil reclamation, boiler scale prevention, and nuclear waste storage.

\section{Experimental methods}

Raw material synthesis and characterization Crystal growth

To control purity, synthetic mineral crystals were produced using a gel-growth method $[13,22]$. A $\sim 0.5 \mathrm{M}$ sodium metasilicate stock solution was prepared by adding $100 \mathrm{~g} \mathrm{Na}_{2} \mathrm{SiO}_{3} \cdot 5 \mathrm{H}_{2} \mathrm{O}$ to $1 \mathrm{~L}$ of reverse osmosis (RO) water (boiled and cooled to remove $\mathrm{CO}_{2}$ ). One drop of bromophenol blue indicator was added to $20 \mathrm{~mL}$ of stock solution, with stirring, and $3 \mathrm{M} \mathrm{HCl}$ was added in small portions until the loss of blue color indicated a $\mathrm{pH}$ of $<4.5$. $\mathrm{SrCl}_{2}, \mathrm{BaCl}_{2}$ or $\mathrm{Pb}(\text { acetate })_{2}$ solution $(0.5 \mathrm{~mL}$, $1 \mathrm{M})$ was added dropwise, with stirring. The solutions were quickly poured into glass test tubes, $2.5 \mathrm{~cm}$ in diameter and $15 \mathrm{~cm}$ long, lightly covered, and allowed to set for 1 week. A $\mathrm{K}_{2} \mathrm{SO}_{4}$ solution $(10 \mathrm{~mL}, 1 \mathrm{M})$ was added slowly to the top of the semi-firm gels, taking care not to disrupt the surface. Crystals grew by diffusion within $1-2$ weeks and were well-formed, ranging from $<100 \mu \mathrm{m}$ to $>500 \mu \mathrm{m}$ in length.

\section{Characterization methods}

Samples from each batch were analyzed using a FEI Quanta 450 field emission gun scanning electron microscope (FEG-SEM) equipped with an EDAX energy- dispersive X-ray (EDS) detector (Adelaide Microscopy, The University of Adelaide) to verify composition and quality.

\section{Leaching/recrystallization tests Reactions in simple solutions}

To elicit information regarding the uptake of competing cations, crystals were exposed to solutions of single cations under various anionic activity and time conditions. Table 1 lists the contents and conditions of the 24 vials.
Half of these were run with only $\mathrm{MCl}_{2}$ solution $(\mathrm{M}=\mathrm{Sr}$, $\mathrm{Ba}$, or $\mathrm{Pb}$ ) while the other half also included $1.6 \mathrm{M} \mathrm{H}_{2} \mathrm{SO}_{4}$ to more closely represent the conditions found in a typical acid leach tank. As expected, white sulfate precipitated immediately in all reaction experiments containing sulfuric acid, resulting in reduced effective concentrations of all three cation solutions. The reduced concentrations should reasonably reproduce actual activities present during processing in a $1.6 \mathrm{M} \mathrm{H}_{2} \mathrm{SO}_{4}$ acid leach solution.

Vials were capped and heated to $60{ }^{\circ} \mathrm{C}$ (typical for Olympic Dam hydrometallurgical processes) for either 40 or $210 \mathrm{~h}$. Without cooling, the surviving crystals were rinsed with $60{ }^{\circ} \mathrm{C} \mathrm{RO}$ water three times, dried, individually selected and embedded in $2.5 \mathrm{~cm}$-round epoxy resin mounts. The mounts were polished, carbon-coated, and imaged in backscatter electron (BSE) mode by SEM. The primary distinction between this experiment and the one below is that these crystals were isolated and only exposed to one additional cation at a time, in great excess.

\section{Crystal analysis by LA-ICP-MS}

Samples from the above set of experiments were analyzed by LA-ICP-MS using an ASI RESOlution-LR ArF excimer laser ablation system equipped with a large format S155 sample chamber (Laurin Technic Inc.) and coupled to an Agilent $7900 \times$ ICP-MS. Transects were performed across each crystal, including at least an extra $10 \mu \mathrm{m}$ on either side in the epoxy to establish a blank. Instrument conditions for the transects were set using a $6 \mu \mathrm{m}$ spot size, fluence $3.5 \mathrm{~J} / \mathrm{cm}^{2}$, repetition rate $10 \mathrm{~Hz}$. The NIST610 reference standard was analyzed in replicate at the beginning, middle, and end of the run, with two sections of 24 transects in-between. Standards were run using a $74 \mu \mathrm{m}$ spot size, fluence $3.5 \mathrm{~J} / \mathrm{cm}^{2}$, repetition rate $10 \mathrm{~Hz}$. Isotopes analyzed were limited to ${ }^{35} \mathrm{Cl},{ }^{88} \mathrm{Sr},{ }^{138} \mathrm{Ba},{ }^{204,206 \text {, }}$

Table 1 Experimental conditions for reactions in simple solutions

\begin{tabular}{|c|c|c|c|c|c|}
\hline Experiment/vial & Crystals & a. $40 \mathrm{~h}$ & b. $40 \mathrm{~h}$ & c. $210 \mathrm{~h}$ & d. $210 \mathrm{~h}$ \\
\hline $5(a-d)$ & $\mathrm{BaSO}_{4}$ & $0.07 \mathrm{M} \mathrm{PbCl}_{2}$ & $\begin{array}{l}\text { 0.07 } \mathrm{M} \mathrm{PbCl}_{2}^{*} \\
\text { 1.6 } \mathrm{M} \mathrm{H}_{2} \mathrm{SO}_{4}\end{array}$ & $0.07 \mathrm{M} \mathrm{PbCl}_{2}$ & $\begin{array}{l}\text { 0.07 } \mathrm{M} \mathrm{PbCl}_{2}^{*} \\
1.6 \mathrm{M} \mathrm{H}_{2} \mathrm{SO}_{4}\end{array}$ \\
\hline $6(a-d)$ & $\mathrm{BaSO}_{4}$ & $0.1 \mathrm{M} \mathrm{SrCl}_{2}$ & $\begin{array}{l}0.1 \mathrm{M} \mathrm{SrCl}_{2}^{*} \\
1.6 \mathrm{M} \mathrm{H}_{2} \mathrm{SO}_{4}\end{array}$ & $0.1 \mathrm{M} \mathrm{SrCl}_{2}$ & $\begin{array}{l}0.1 \mathrm{M} \mathrm{SrCl}_{2}^{*} \\
1.6 \mathrm{M} \mathrm{H}_{2} \mathrm{SO}_{4}\end{array}$ \\
\hline $7(a-d)$ & $\mathrm{SrSO}_{4}$ & $0.1 \mathrm{M} \mathrm{BaCl}_{2}$ & $\begin{array}{l}0.1 \mathrm{M} \mathrm{BaCl}_{2}^{*} \\
1.6 \mathrm{M} \mathrm{H}_{2} \mathrm{SO}_{4}\end{array}$ & $0.1 \mathrm{MBaCl}_{2}$ & $\begin{array}{l}0.1 \mathrm{M} \mathrm{BaCl}_{2}^{*} \\
1.6 \mathrm{M} \mathrm{H}_{2} \mathrm{SO}_{4}\end{array}$ \\
\hline $8(a-d)$ & $\mathrm{SrSO}_{4}$ & $0.07 \mathrm{M} \mathrm{PbCl}_{2}$ & $\begin{array}{l}\text { 0.07 } \mathrm{M} \mathrm{PbCl}_{2}^{*} \\
1.6 \mathrm{M} \mathrm{H}_{2} \mathrm{SO}_{4}\end{array}$ & $0.07 \mathrm{M} \mathrm{PbCl}_{2}$ & $\begin{array}{l}\text { 0.07 } \mathrm{M} \mathrm{PbCl}_{2}^{*} \\
1.6 \mathrm{M} \mathrm{H}_{2} \mathrm{SO}_{4}\end{array}$ \\
\hline $9(a-d)$ & $\mathrm{PbSO}_{4}$ & $0.1 \mathrm{M} \mathrm{SrCl}_{2}$ & $\begin{array}{l}0.1 \mathrm{M} \mathrm{SrCl}_{2}^{*} \\
1.6 \mathrm{M} \mathrm{H}_{2} \mathrm{SO}_{4}\end{array}$ & $0.1 \mathrm{M} \mathrm{SrCl}_{2}$ & $\begin{array}{l}0.1 \mathrm{M} \mathrm{SrCl}_{2}^{*} \\
1.6 \mathrm{M} \mathrm{H}_{2} \mathrm{SO}_{4}\end{array}$ \\
\hline $10(a-d)$ & $\mathrm{PbSO}_{4}$ & $0.1 \mathrm{M} \mathrm{BaCl}_{2}$ & $\begin{array}{l}0.1 \mathrm{M} \mathrm{BaCl}_{2}^{*} \\
1.6 \mathrm{M} \mathrm{H}_{2} \mathrm{SO}_{4}\end{array}$ & $0.1 \mathrm{MBaCl}_{2}$ & $\begin{array}{l}0.1 \mathrm{M} \mathrm{BaCl}_{2}^{*} \\
1.6 \mathrm{M} \mathrm{H}_{2} \mathrm{SO}_{4}\end{array}$ \\
\hline
\end{tabular}


${ }^{207,}{ }^{208} \mathrm{~Pb}$, and ${ }^{226} \mathrm{Ra}$. Due to the simple, stoichiometric composition of the crystals, elemental concentration data (in $\mathrm{ppm}$ ) was calculated using a modified version of the internal standard method [19] with an additional minor drift correction. To avoid irregularities at grain edges, concentration values were calculated in ppm normalized to $1,000,000$ instead of $\mathrm{ppm}_{\text {(total count) }}$. Isotopic concentrations were converted to elemental concentrations using global isotopic abundances [12]. The time-resolved transect data from the ICP-MS (in seconds) was converted to distance $(\mu \mathrm{m})$ by direct comparison between transect traces and their corresponding BSE image, and are therefore estimates. Calculated concentration data was smoothed using a 3-period moving average to minimize electronic spikes.

Despite clean EDS spectra, LA-ICP-MS analyses revealed that the crystals were slightly contaminated with other cations. As a result, the baryte crystals contained approximately $10 \mathrm{ppm} \mathrm{Pb}$ and $140 \mathrm{ppm} \mathrm{Sr}$; the celestite contained approximately $10 \mathrm{ppm}$ each of $\mathrm{Ba}$ and $\mathrm{Pb}$; and the anglesite contained around $165 \mathrm{ppm} \mathrm{Ba}$ and $115 \mathrm{ppm}$ Sr. The $\mathrm{SrCl}_{2}, \mathrm{BaCl}_{2}$, and $\mathrm{PbCl}_{2}$ solutions also contained ppm quantities of contaminants, but analysis of the data suggests that contamination of both crystals and solutions proved to be many orders of magnitude lower in concentration than the effects observed in crystalline reaction zones and therefore had only a minimal effect on the experiments.

\section{Supersaturation and nucleation rate calculations}

Using the equations from Söhnel [40], Sangwal [35], and Pina and Putnis [23], supersaturation and nucleation rates were calculated for the above experiments. Briefly, the equation for supersaturation $S(x)$ is:

$$
S(x)=\sqrt{\frac{a\left(C^{2+}\right)^{1-x} a\left(B^{2+}\right)^{x} a\left(A^{2-}\right)}{\left(K_{C A} a_{C A}\right)^{1-x}\left(K_{B A} a_{B A}\right)^{x}}}
$$

where $B$ represents $\mathrm{Sr}, \mathrm{Ba}$, or $\mathrm{Pb}$ of the crystal matrix; $C$ represents $\mathrm{Sr}, \mathrm{Ba}$, or $\mathrm{Pb}$ in the added chloride solution, $A=\left(\mathrm{SO}_{4}{ }^{2-}\right) ; \mathrm{K}_{\mathrm{CA}}$ and $\mathrm{K}_{\mathrm{BA}}$ represent the appropriate solubility product constants at $60{ }^{\circ} \mathrm{C}$; and $x$ and $(1-x)$ represent the mole fractions of $B$ and $C$, respectively. Solid solutions are assumed to be complete and ideal, simplifying the activity fractions $a_{C A}$ and $a_{B A}$ to 1 . Concentrations, and subsequently activities, were estimated from the extrapolation/interpolation of data from various sources including Linke and Seidell [18], Krumgalz [16], initial experimental concentrations, and solubility products listed in Table 2. Experimental conditions prevented the possibility of measuring actual concentrations, mostly due to size constraints, so estimates were made based on solubilities of $\mathrm{BaSO}_{4}, \mathrm{SrSO}_{4}$, and $\mathrm{PbSO}_{4}$ in neutral
Table 2 Solubility data for selected sulfates

\begin{tabular}{|c|c|c|c|c|}
\hline Compound & $K_{\mathrm{sp}}\left(60^{\circ} \mathrm{C}\right)$ & $V_{m o l}\left(m^{3}\right)^{d}$ & $\operatorname{CIR}^{\mathrm{e}}(\AA)$ & Sol $\left(\mathrm{kg}^{-1} \mathrm{H}_{2} \mathrm{O}\right)$ \\
\hline $\mathrm{BaSO}_{4}^{\mathrm{b}}$ & $2.216 \times 10^{-10}$ & $8.67 \times 10^{-29}$ & 1.75 & $3.62 \mathrm{mg}\left(60^{\circ} \mathrm{C}\right)$ \\
\hline $\mathrm{CaSO}_{4} \cdot 2 \mathrm{H}_{2} \mathrm{O}^{\mathrm{b}}$ & $2.137 \times 10^{-5}$ & $12.38 \times 10^{-29}$ & 1.26 & $2559 \mathrm{mg}\left(60^{\circ} \mathrm{C}\right)$ \\
\hline $\mathrm{CaSO}_{4} \cdot 0.5 \mathrm{H}_{2} \mathrm{O}^{\mathrm{b}}$ & $4.971 \times 10^{-5}$ & $8.80 \times 10^{-29}$ & 1.26 & $4212 \mathrm{mg}\left(60^{\circ} \mathrm{C}\right)$ \\
\hline $\mathrm{CaSO}_{4}^{\mathrm{b}}$ & $1.674 \times 10^{-5}$ & $7.64 \times 10^{-29}$ & 1.26 & $1670 \mathrm{mg}\left(60^{\circ} \mathrm{C}\right)$ \\
\hline $\mathrm{SrSO}_{4}^{\mathrm{b}}$ & $1.775 \times 10^{-7}$ & $7.68 \times 10^{-29}$ & 1.58 & $100 \mathrm{mg}\left(60^{\circ} \mathrm{C}\right)$ \\
\hline $\mathrm{PbSO}_{4}^{\mathrm{a}}$ & $2.53 \times 10^{-8}$ & $7.94 \times 10^{-29}$ & 1.63 & $63.4 \mathrm{mg}\left(60^{\circ} \mathrm{C}\right)$ \\
\hline $\mathrm{RaSO}_{4}^{\mathrm{c}}$ & $1.78 \times 10^{-10}$ & $9.24 \times 10^{-29}$ & 1.84 & $\sim 4 \mathrm{mg}\left(60^{\circ} \mathrm{C}\right)$ \\
\hline
\end{tabular}

CIR crystal ionic radius of the cation (XII coordination) except Ca (VIII coordination)

Data sources: ${ }^{\mathrm{a}}$ Haynes [12]; ${ }^{\mathrm{b}} \mathrm{Krumgalz} \mathrm{[16];}{ }^{\mathrm{c} B r o w n}$ et al. [3]; ${ }^{\mathrm{d}} \mathrm{https} / / /$ www.minda t.org, and references within; ${ }^{\text {eShannon [39] }}$

chloride, acid chloride, neutral sulfate, and acid sulfate conditions at $60{ }^{\circ} \mathrm{C}$. Although this does introduce some error, variation of the activities resulted in only minor changes in the trend curves produced-and even then, only in magnitude. The shape of the trend curves as well as the maximum $\mathrm{X}_{\mathrm{BA}}$ values remained consistent.

The nucleation rate function $J(x)$ is calculated by:

$$
J(x)=\Gamma(x) \exp \left[\frac{-B \sigma^{3}(x) \Omega^{2}(x)}{k^{3} T^{3}(\ln S(x))^{2}}\right]
$$

where $\Gamma(x)$ is the preexponential factor, estimated from molecular volume (Table 2); $\Omega(x)$ is molecular volume (Table 2); $\sigma(x)$ is the interfacial free energy, estimated from $\mathrm{K}_{\mathrm{sp}}$ values (Table 2); $B$ represents a geometric factor dependent on nucleus shape; $k$ is Boltzmann's constant $\left(1.38 \times 10^{-23} \mathrm{~J} / \mathrm{K}\right) ; T$ is temperature in Kelvin; and $S(x)$ is the supersaturation factor from the equation above. A full description of these equations and their derivations can be found in Pina and Putnis [23] and references within. The reasoning behind these calculations is that thermodynamics alone do not always reproduce the observed results. Nucleation rates may significantly outweigh supersaturation ratios, and crystallization products may form contrary to solubility products [29].

\section{Reactions in the presence of different sulfates}

Two to five crystals of each compound $(\sim 200 \mu \mathrm{g})$ were placed together in $4.5 \mathrm{~mL}$ Exetainer glass screw-top vials. More or fewer crystals were added depending on size to roughly balance representation, but the samples were not weighed. Solutions $(50 \mu \mathrm{L})$ were added to each vial. Table 3 lists the contents of the vials from experiments 1-4. Vials were capped and placed in a $60^{\circ} \mathrm{C}$ oven for $30 \mathrm{~h}$. After the allotted time, remaining crystals were rinsed while hot and sample preparation was completed in the same manner as above. Note that for this experiment all 
Table 3 Experimental conditions for reaction experiments in the presence of different sulfates

\begin{tabular}{llll}
\hline $\begin{array}{l}\text { Experiment/ } \\
\text { vial }\end{array}$ & Crystals & Solution & Approx. pH \\
\hline 1 & $\mathrm{Sr}, \mathrm{Ba}, \mathrm{Pb}$ sulfates & $0.1 \mathrm{M} \mathrm{K}_{2} \mathrm{SO}_{4}$ & 7 \\
2 & $\mathrm{Sr}, \mathrm{Ba}, \mathrm{Pb}$ sulfates & $0.08 \mathrm{M} \mathrm{H}_{2} \mathrm{SO}_{4}$ & 1 \\
3 & $\mathrm{Sr}, \mathrm{Ba}, \mathrm{Pb}$ sulfates & $0.1 \mathrm{M} \mathrm{NaCl}$ & 7 \\
4 & $\mathrm{Sr}, \mathrm{Ba}, \mathrm{Pb}$ sulfates & $0.12 \mathrm{M} \mathrm{HCl}$ & 1 \\
\hline
\end{tabular}

three cations are in direct competition in the same vials, and that the only source of $\mathrm{Sr}^{2+}, \mathrm{Ba}^{2+}$, and $\mathrm{Pb}^{2+}$ are from material dissolved from the crystals themselves.

\section{Crystal analysis using NanoSIMS}

Samples were analyzed on the Cameca NanoSIMs 50L at the Centre for Microscopy, Characterisation, and Analysis (CMCA), located at the University of Western Australia, Perth, using previously established settings [33]. To best explore surface addition, replacement, or diffusive activity, sites near the edges of grains were mapped. A Hyperion (H200) RF plasma oxygen ion source was used for all analyses. The instrument was operated in multicollection mode, with five of the seven available detectors tuned to ${ }^{28} \mathrm{Si},{ }^{40} \mathrm{Ca},{ }^{88} \mathrm{Sr}$, ${ }^{138} \mathrm{Ba}$, and ${ }^{206} \mathrm{~Pb}$. The additional two detectors were tuned to rare-earth element isotopes used in a separate experiment (and will thus not be referenced here). Maps of ${ }^{28} \mathrm{Si}$ and ${ }^{40} \mathrm{Ca}$ were included as quality control and to confirm that the silicon and calcium contribution to crystal growth was minimal. Similar instrument settings were used for all mapping $(50 \times 50 \mu \mathrm{m}$ raster area, $50 \mathrm{pA}$ ion current, D1 $=2$, $\mathrm{ES}=2, \mathrm{AS}=0,512 \times 512 \mathrm{px}, 3$ planes, $5 \mathrm{~ms} / \mathrm{px}$, effective beam diameter $\approx 400 \mathrm{~nm}$ ).

Images were processed using ImageJ $[36,37]$ and the OpenMIMS plugin [25]. The color convention of Sr (in red), $\mathrm{Ba}$ (green), and $\mathrm{Pb}$ (blue) has been adopted for all images.

\section{Results and discussion \\ Crystal characteristics}

All three sulfates crystallize in the orthorhombic crystal system, dipyrimidal $(2 / m 2 / m 2 / m)$ crystal class. $\mathrm{SrSO}_{4}$ formed slightly rounded orthorhombic prisms with dipyrimidal (chisel) terminations. Many crystals exhibited additional symmetric lateral growths (ears) near the prism/dipyramid interface. $\mathrm{BaSO}_{4}$ formed as double orthorhombic blades, centrally attached in bow-tie fashion. $\mathrm{PbSO}_{4}$ grew in well-formed euhedral prisms with varying dipyrimidal terminations. Figure 1 shows examples of the crystals produced from gel growth. Spectra of all three compounds were clean and sharp, with minimal traces of silicon found in the center of some of the grains but very little near the edges. This is not uncommon in crystals grown in a silica gel matrix, but nanoSIMS imaging revealed that this was not a factor in the experiment.

Although these synthetic crystals do not adhere to the strict definition of a mineral [8], the terms celestite, baryte, and anglesite are used interchangeably with $\mathrm{SrSO}_{4}$, $\mathrm{BaSO}_{4}$, and $\mathrm{PbSO}_{4}$, respectively, in the following sections. These crystals are designed to be simple but accurate proxies for the natural minerals in question, and evidence suggests that behaviors of the natural and artificial-with respect to these experiments-are aligned and would therefore apply equally to both.

\section{Leaching/recrystallization in simplified media}

Figure 2 shows transects from barytes exposed to $\mathrm{PbCl}_{2}$ solution (experiments 5a-d), The BSE image of experiment $5 \mathrm{~d}$ shows the typical bowtie morphology of the baryte crystals. The crystal in experiment $5 \mathrm{~b}$ has tipped over and the bottom surface has been broken off. Thin,
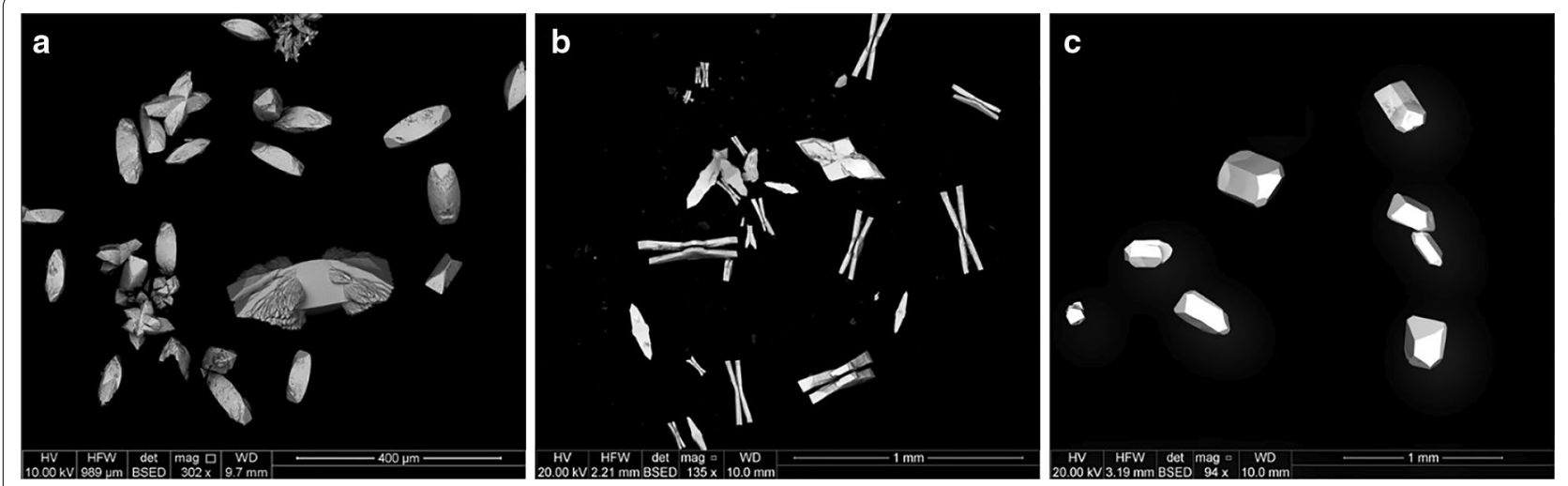

Fig. $1 \mathrm{BSE}$ images of laboratory-grown $\mathrm{SrSO}_{4}(\mathbf{a}), \mathrm{BaSO}_{4}(\mathbf{b})$, and $\mathrm{PbSO}_{4}$ (c) 

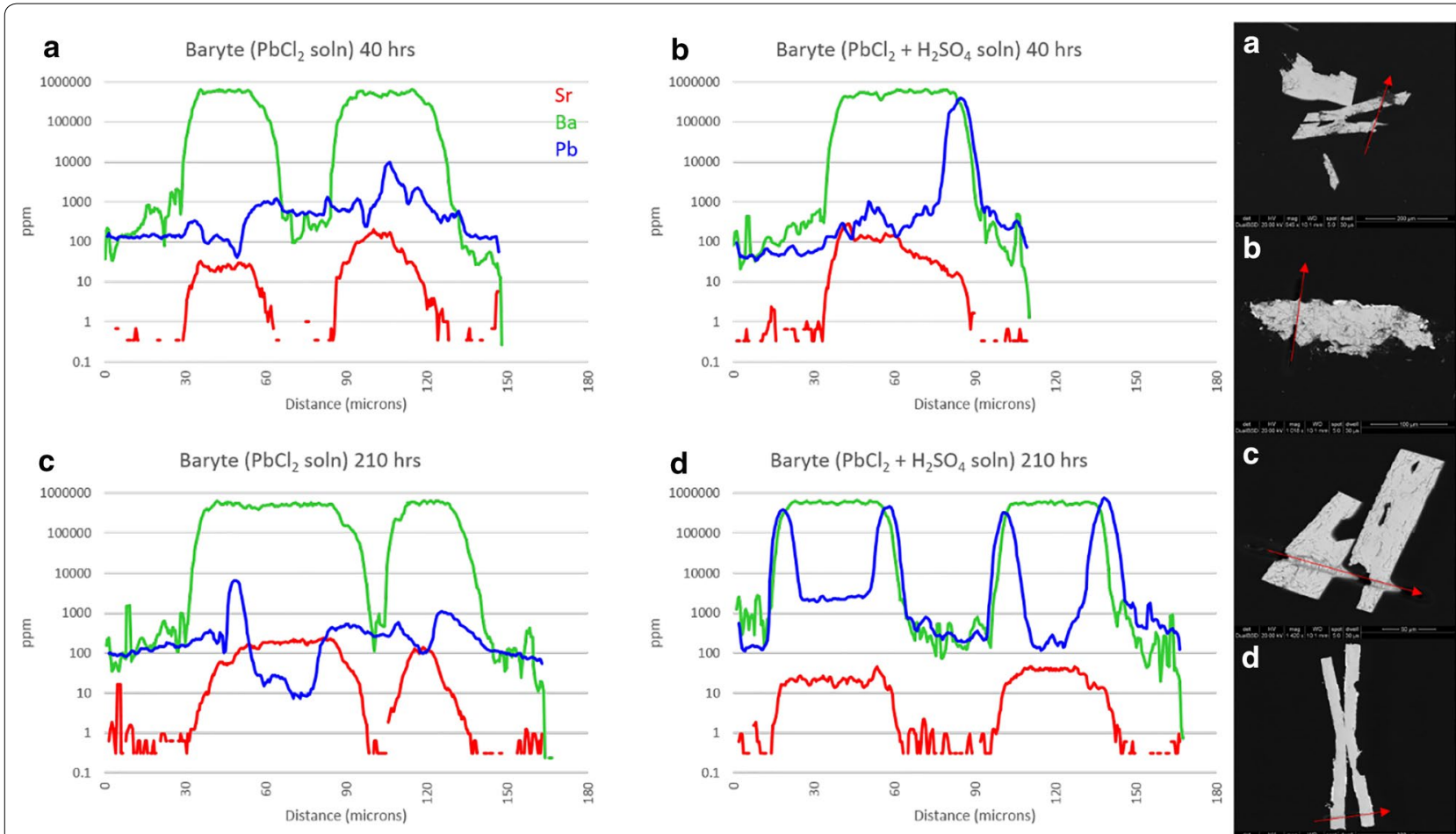

Fig. 2 Results from experiment 5(a-d), baryte exposed to $\mathrm{Pb}^{2+}$ solution. LA-ICP-MS transects (a-d) correlate with BSE images (a-d). Red arrows show location and direction of laser ablation route

bright overgrowths of Pb-rich sulfate can be clearly seen in experiment $5 \mathrm{~b}$ and $\mathrm{d}$, with no visible surface effects in experiment $5 \mathrm{a}$ and $\mathrm{c}$. The $\mathrm{Sr}$ background in the crystals is evident (everywhere $<200 \mathrm{ppm}$ ), with lower concentration areas the result of partial leaching.

Although reaction time seems to have had little effect on the experiment, the presence of sulfate has had a profound effect. Overgrowth of $\mathrm{PbSO}_{4}$ in experiment $5 \mathrm{~b}$ and $5 \mathrm{~d}$ occurs almost universally, though non-uniformly, up to $6 \mu \mathrm{m}$-thick in some areas. In transects, overgrowth is represented where the minor trace $(\mathrm{Pb}-$ blue $)$ crosses over the major trace ( $\mathrm{Ba}-$ green). All four surfaces of $5 \mathrm{~d}$ show overgrowth in both BSE and LA-ICP-MS. Only one surface of experiment $5 \mathrm{~b}$ shows the same, as the bottom surface was clearly broken during mounting. The roughly parabolic $\mathrm{Pb}$ traces appear wider than the overgrowth layers visible in the BSE image due to the relatively large beam width, with the increased $\mathrm{Pb}$ intensity beginning with the leading edge of the beam and ending with the trailing edge. The resulting width displayed by ICP-MS is the overgrowth layer plus the beam width plus any diffusive zone of the crystal face. Since the edge zones appear to be roughly symmetric (surface vs. interior), it is likely that diffusion of $\mathrm{Pb}$ into the $\mathrm{BaSO}_{4}$ structure was minimal. Crystals from experiment $5 \mathrm{a}$ and $\mathrm{c}$ show no evidence of $\mathrm{Pb}$ in BSE images, with relatively clean, sharp crystal surfaces. Transects of the same crystals indicate little to no uptake of $\mathrm{Pb}$ either as overgrowth on, or diffusion into, the crystal surfaces. The few enriched regions which are present may represent either limited uptake or surface contamination due to polishing, but the $\mathrm{Pb}$ concentrations there are nearly two orders of magnitude lower than those in the sulfate-available experiments.

Barytes exposed to $\mathrm{SrCl}_{2}$ solution (experiments 6a, c, and d) are shown in Fig. 3. Unfortunately, the crystal from experiment $6 \mathrm{~b}$ was lost. The $\mathrm{Pb}$ background in all crystals was consistently low, around $10 \mathrm{ppm}$, and had little impact on the experiment. The second laser transect visible in 6a was a test of instrument conditions. Although $6 \mathrm{~b}$ is missing, it appears that the overall result of experiment $6(\mathrm{a}-\mathrm{d})$ is similar to experiment $5(\mathrm{a}-\mathrm{d})$, with reaction time having little effect but sulfate activity having a pronounced effect on the uptake of Sr. A dark overgrowth layer in $6 \mathrm{~d}$ is clearly visible in the BSE image (to $15 \mu \mathrm{m}$-thick), although the ICP-MS data confirms that this layer is not pure $\mathrm{SrSO}_{4}$ but is predominantly $\mathrm{BaSO}_{4}$ with up to $20 \% \mathrm{Sr}$ on a metals basis (m.b.). Consistent sloping of both $\mathrm{Ba}$ and $\mathrm{Sr}$ traces on the right side of both leaves indicates that the entire crystal is mounted in the epoxy at an angle, sloping upwards towards the "northwest" into the frame. No visible or measured Sr-rich edge 

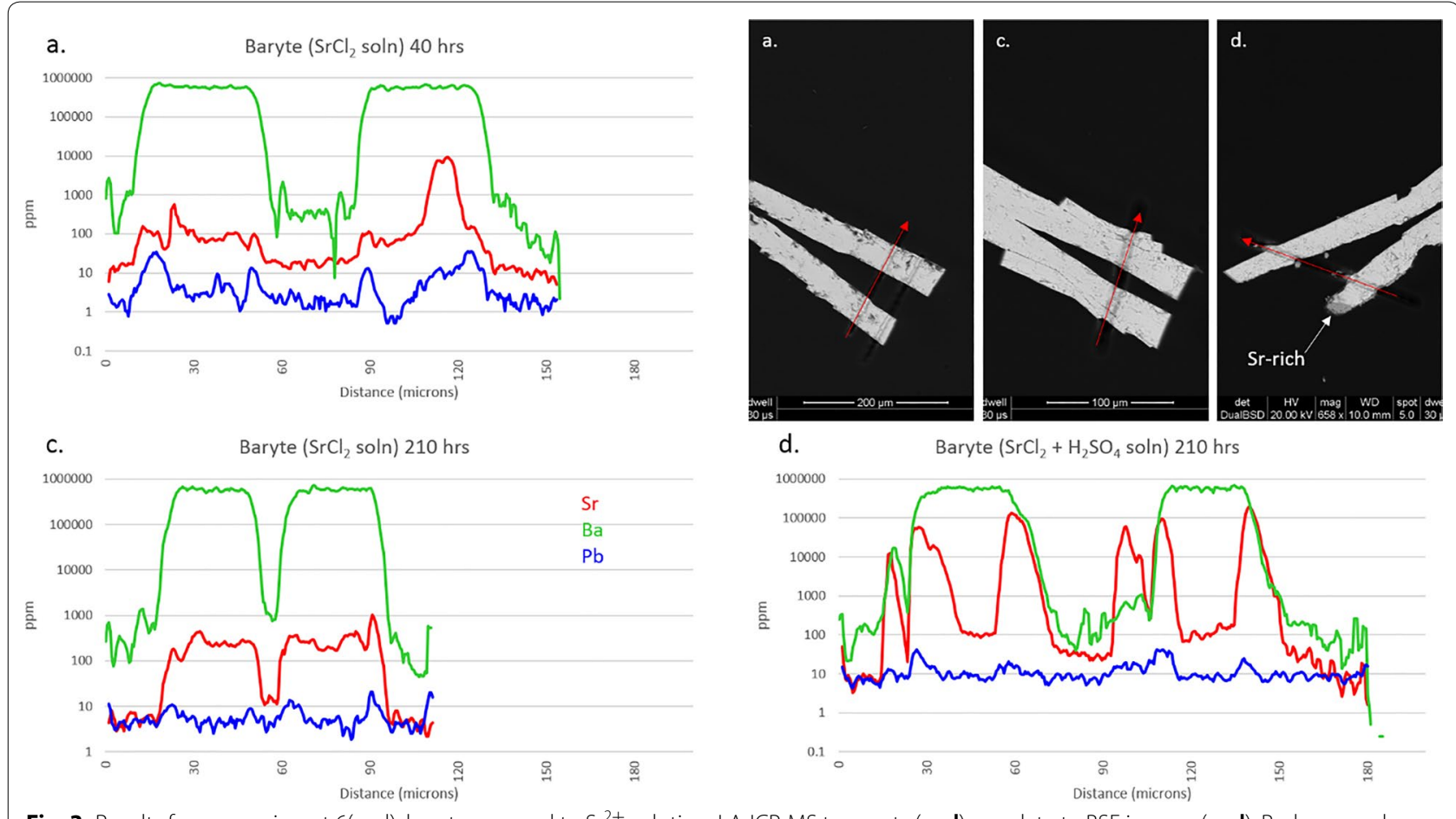

Fig. 3 Results from experiment 6(a-d), baryte exposed to $\mathrm{Sr}^{2+}$ solution. LA-ICP-MS transects (a-d) correlate to BSE images (a-d). Red arrows show location and direction of laser ablation route. The baryte from vial $6 \mathrm{~b}$ was lost

zones are evident in either 6 a or $6 \mathrm{c}$, although one spot on the interior of $6 \mathrm{a}$ approaches $2 \% \mathrm{Sr}$.

Figure 4 shows the results of experiment $7 \mathrm{a}-\mathrm{d}$ (celestite exposed to $\mathrm{BaCl}_{2}$ solution). $\mathrm{Pb}$ in the crystal interiors generally ranges from 10 to $50 \mathrm{ppm}$, although it is suggested from edge zone concentrations (to $400 \mathrm{ppm} \mathrm{Pb}$ ) that the $\mathrm{BaCl}_{2}$ solution probably contained some $\mathrm{Pb}$. Uptake of $\mathrm{Pb}$ into grain edges mimics uptake of $\mathrm{Ba}$ but remains 1-3 orders of magnitude lower in concentration. All celestite crystals show visible porosity, the result of growth in a silica gel matrix. Slight enrichments in both $\mathrm{Ba}$ and $\mathrm{Pb}$ in grain centers are likely a result of this. Unlike the baryte experiments, it appears that reaction time does have some effect on the uptake of Ba by celestite, although this may only apply to low-sulfate activity conditions. Incorporation of Ba remains low at $40 \mathrm{~h}(<1 \%$, m.b.) but increases to $>70 \%$ in thin edge zones at $210 \mathrm{~h}$. This may actually approach $100 \%$, but ICP-MS resolution is limited by spot size. Crystals $7 \mathrm{a}$ and $7 \mathrm{c}$ maintain sharp features, and a bright Ba-rich replacement zone can be seen on BSE images for 7c although this rarely exceeds $1 \mu \mathrm{m}$ in thickness. This is confirmed by ICP-MS as the $\mathrm{Ba}$ trace overlaps the $\mathrm{Sr}$ trace on both grain edges, with the right edge appearing more pronounced. This is likely from crystal mounting angle, suggested by the trailing edge of the laser transect on the right side of the crystal. Crystals 7b and 7d show signs of surface dissolution, amplified at terminations. Unlike the acid sulfate experiment from Phase 1, no overgrowth layers are visible. Independent of time, Ba uptake in high-sulfate activity conditions appears to stabilize around $2-2.5 \%$ (m.b.). Ba concentration appears to positively correlate with porosity in $7(b, d)$ but not $7(a, c)$, suggesting that freshly precipitated $\mathrm{BaSO}_{4}$ may be trapped in crystal pores.

Transects of celestite exposed to $\mathrm{PbCl}_{2}$ solution (experiments $8 \mathrm{a}-\mathrm{d}$ ) are presented in Fig. 5. The impact of extraneous $\mathrm{Ba}$ is minimal, with slightly higher concentrations in crystal centers which is likely the result of porosity. All crystal faces are primarily sharp with little evidence of surface dissolution, although $8 \mathrm{~b}$ has both clean and rough surfaces. Pb-rich sites are evident in all four BSE images, primarily as nucleated spots as opposed to uniform layers (although both exist). These spots may be freshly precipitated $\mathrm{PbSO}_{4}$ adhering to crystal surfaces or Pb-rich sulfates which grew during the experiment-it is very difficult to distinguish. $\mathrm{Pb}$ concentrations appear to be higher in longer experiments, with an increase from 3.5\% $\mathrm{Pb}$ at $40 \mathrm{~h}$ to $>90 \% \mathrm{~Pb}$ at $210 \mathrm{~h}$. Realistically, however, this may be the result of the laser transect crossing-or not crossing-a precipitated $\mathrm{PbSO}_{4}$ surface particle, so any broad statements about the effect of reaction time would be unsupported. In comparison, porosity clearly has a pronounced influence on $\mathrm{Pb}$ uptake, as seen from $8 \mathrm{c}$. The left half of the crystal is enriched in $\mathrm{Pb}$, which correlates 

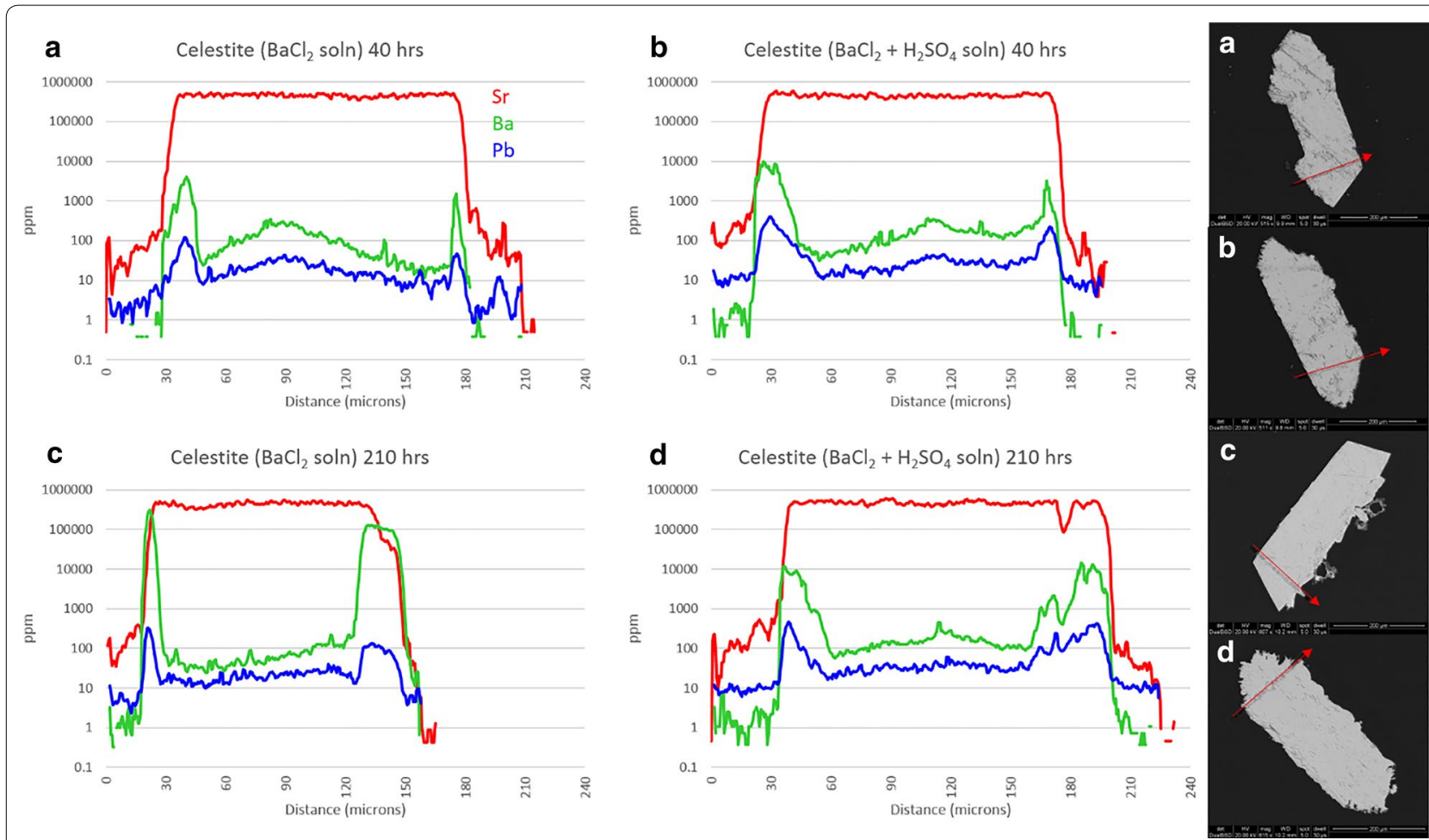

Fig. 4 Results from experiment 7(a-d), celestite exposed to Ba ${ }^{2+}$ solution. LA-ICP-MS transects (a-d) correlate with BSE images (a-d). Red arrows show location and direction of laser ablation route

perfectly with the high porosity region as seen in the BSE image. This is likely the result of enhanced incorporation of $\mathrm{Pb}$ due to increased surface area (and not the result of ineffective rinsing of residual $\mathrm{PbCl}_{2}$ solution from pores) as the ${ }^{35} \mathrm{Cl}$ concentration remains minimal across both regions. With the exception of Pb-rich spots, it appears that maximum uptake of $\mathrm{Pb}$ remains around $2 \%$ regardless of reaction time or sulfate activity.

Anglesite reactions with $\mathrm{SrCl}_{2}$ solution (experiments 9a-d) are presented in Fig. 6. The crystals remained euhe$\mathrm{dral}$, although some porosity is evident in 9a and 9b. This is likely due to growth rate, as the crystals which grew quickly (3-4 days) tended to have higher porosity than those which took 2 weeks or longer to form in the silica gel. Consistent concentrations of $\mathrm{Sr}$ in the center of all 4 grains is clear evidence that the extent of porosity had no effect on uptake here, in contradiction to the celestite experiments. Dark, $\mathrm{Sr}$-rich rims are visible to some extent on all four crystals: on $9 \mathrm{a}$ and $9 \mathrm{c}$ as a thin, irregular layer $(<1 \mu \mathrm{m})$ on all surfaces; on $9 \mathrm{~b}$ as thick $(10 \mu \mathrm{m})$ replacement zones on the lower left and upper right surfaces $\{101, \overline{\mathbf{1}} 0 \overline{\mathbf{1}}\}$ with an overlying $2 \mu \mathrm{m}$ layer of very high-Sr sulfate covering every surface except $\{\mathbf{1 0 1}\}$; and on $9 \mathrm{~d}$ as very patchy $\mathrm{Sr}$-rich replacement zones to $25 \mu \mathrm{m}$ thick in some areas, but completely absent in others. As for the preferential reaction zones of sample 9b, anisotropic growth based on crystallographic orientation has been noted in baryte [24], and likely extends to the entire class of similar sulfates.

Neutral uptake of Sr into anglesite (9a, 9c) is sharp and thin, with the outer $1 \mu \mathrm{m}$ layer surpassing $\mathrm{Sr}: \mathrm{Pb}$ of 1.2. The $\mathrm{Sr}$-rich zones of $9 \mathrm{~b}$ also reach 1.2, but the ubiquitous thin overgrowth layer approaches 2.8 . On $9 \mathrm{~d}$, however, the diffuse Sr-rich regions only contain about 30\% $\mathrm{Sr}$ (m.b.). Interestingly, Sr concentrations in grain edges seem to stabilize around 100,000 ppm independent of sulfate activity, reaction time, or reaction zone width.

Figure 7 shows anglesite reactions in $\mathrm{Ba}$ solutions (experiments 10a-d). Background $\mathrm{Sr}$ concentrations remain a consistent $100 \mathrm{ppm}$ and do not affect the results. Crystals from experiments 10a and 10c are still euhedral and sharp, with no uptake or overgrowth of $\mathrm{Ba}$ visible in BSE images. Acid-leached crystals, however, show signs of significant surface reactions with rounded edges and dissolution/recrystallization textures extending up to $40 \mu \mathrm{m}$ deep. LA-ICP-MS transects show Ba uptake in these reaction zones, but only to about $3 \mathrm{wt} \%$. Time seems to have played a minor role, with Ba concentrations only slightly increased in 210 -h experiments. 

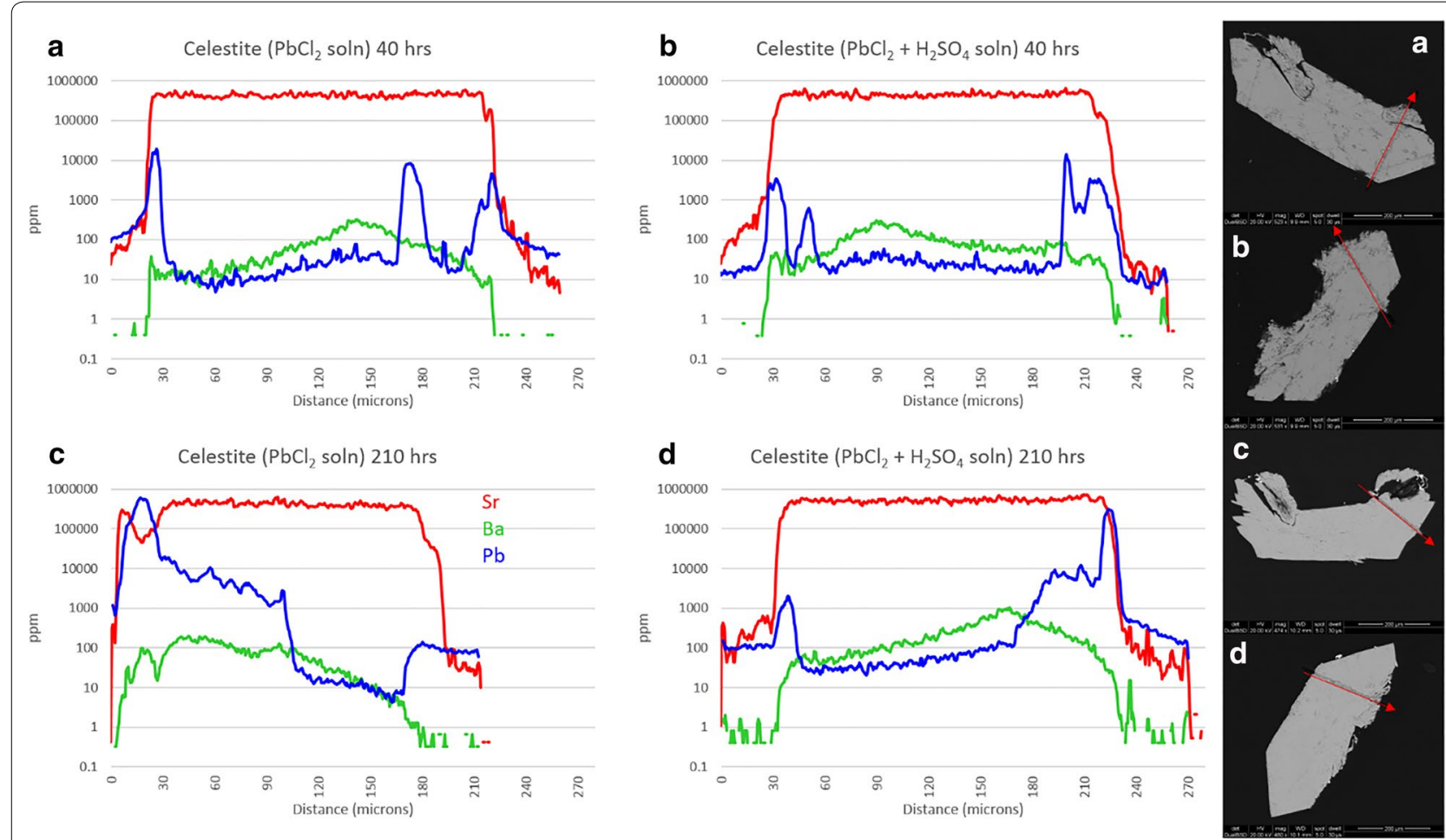

Fig. 5 Results from experiment 8(a-d), celestite exposed to $\mathrm{Pb}^{2+}$ solution. LA-ICP-MS transects (a-d) correlate with BSE images (a-d). Red arrows show location and direction of laser ablation route

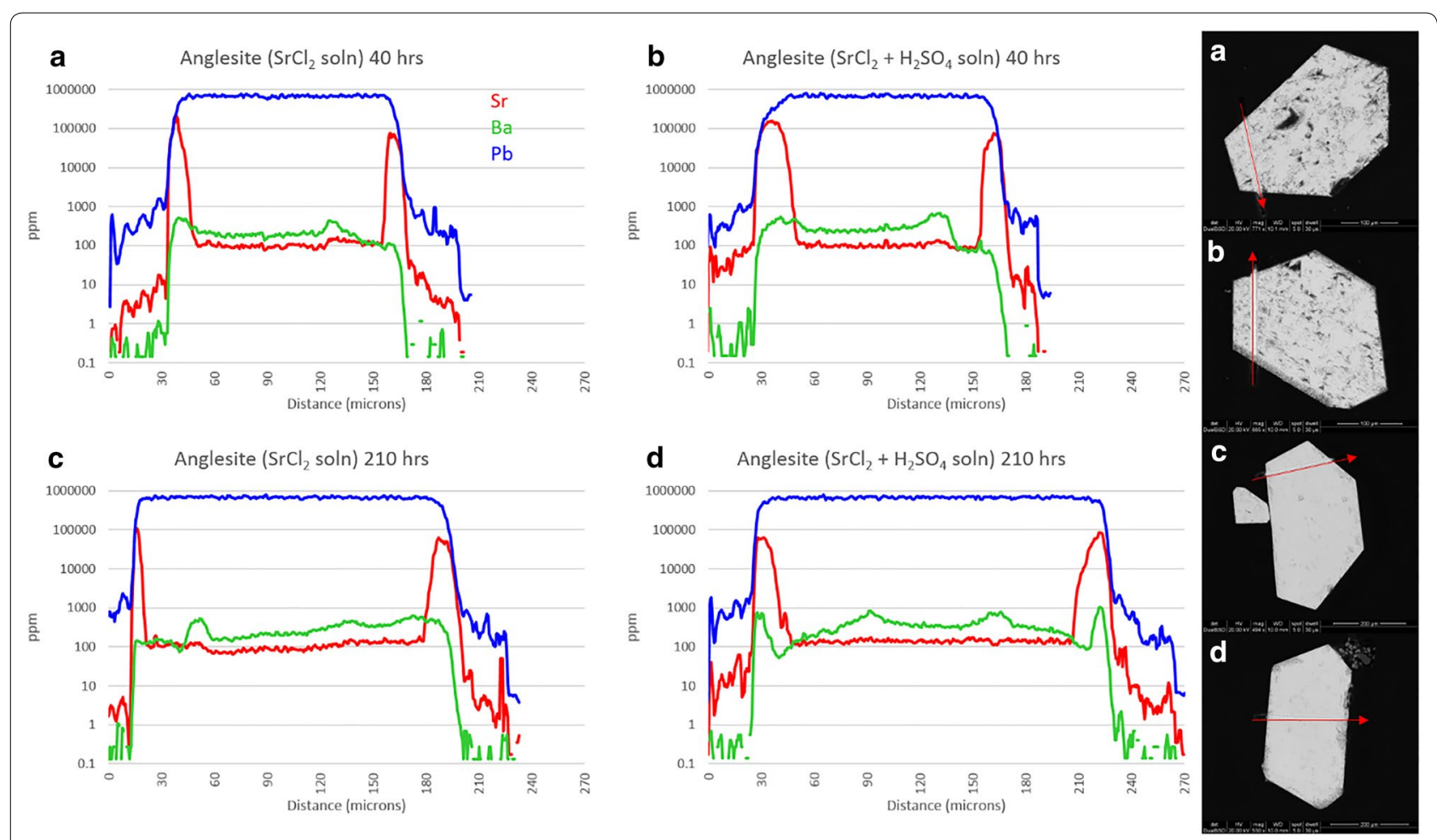

Fig. 6 Results from experiment 9(a-d), anglesite exposed to $\mathrm{Sr}^{2+}$ solution. LA-ICP-MS transects (a-d) correlate with BSE images (a-d). Red arrows show location and direction of laser ablation route 

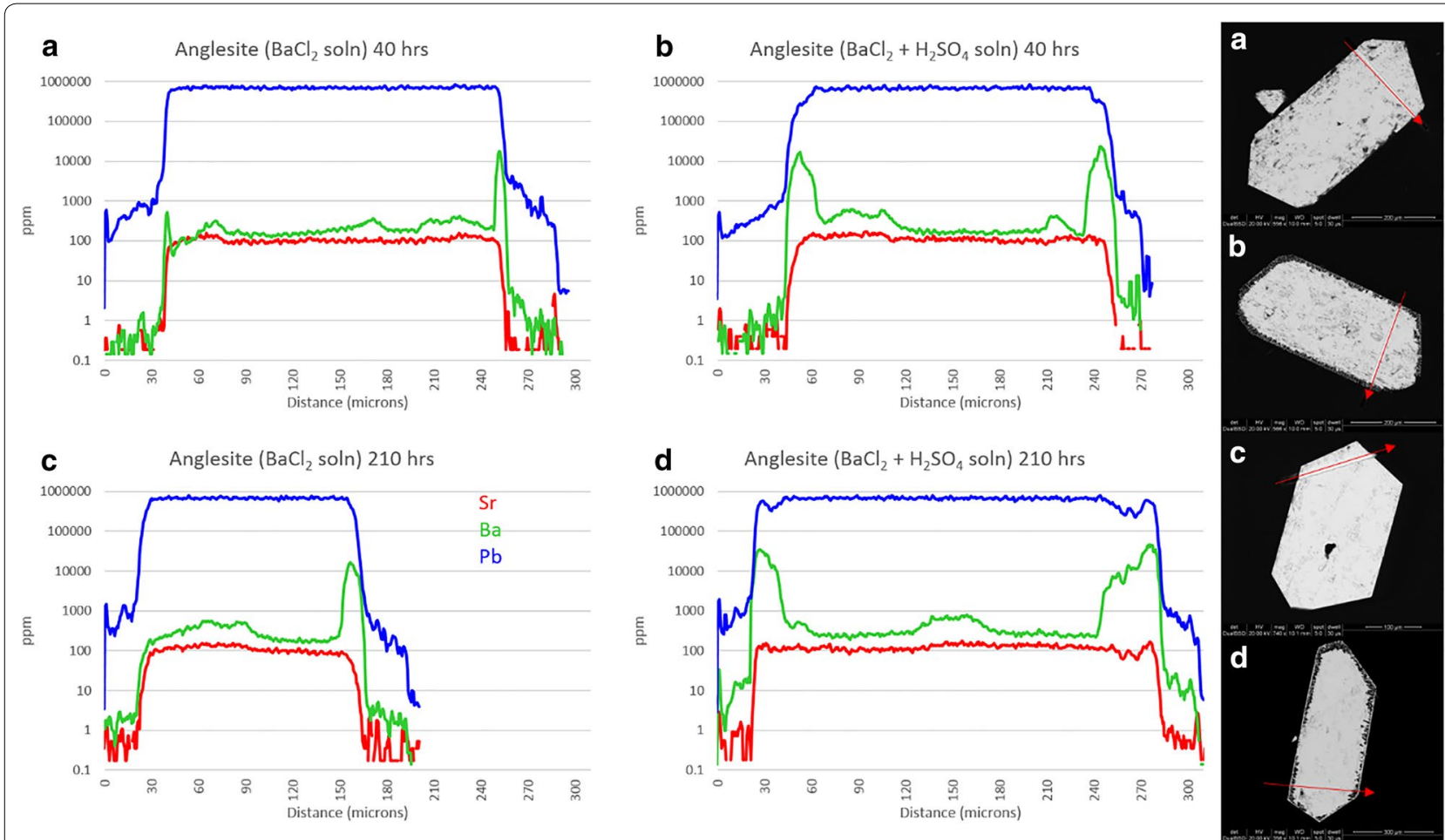

Fig. 7 Results from experiment 10(a-d), anglesite exposed to Ba ${ }^{2+}$ solution. LA-ICP-MS transects (a-d) correlate with BSE images (a-d). Red arrows show location and direction of laser ablation route

\section{Interpretation and discussion}

For baryte in experiment $5 \mathrm{a}-\mathrm{d}$, the $S(x)$ and $J(x)$ calculations are in agreement with experimental observations. With access to only $\mathrm{PbCl}_{2}$, supersaturation remains low and nucleation rate is so low as to be effectively zero. Accordingly, virtually no $\mathrm{Pb}$ is diffused into, or crystallized on the surface of, baryte (Fig. 2a, c). In $\mathrm{PbCl}_{2}+\mathrm{H}_{2} \mathrm{SO}_{4}$, however, the supersaturation function is significantly higher with a maximum of 100 at $\mathrm{X}_{\mathrm{BaSO} 4}=0.66$. Although this may imply that $\mathrm{BaSO}_{4}$ crystallization would be slightly favored, the nucleation rate maximum of $\sim 1.2 \times 10^{14}$ nuclei $/ \mathrm{cm}^{3} \mathrm{~s}$ is actually found at $\mathrm{X}_{\mathrm{PbSO} 4}=0.9$ indicating that $\mathrm{PbSO}_{4}$ nucleation is heavily favored. Figure $2 \mathrm{~b}$, d shows precisely this with thick, nearly pure $\mathrm{PbSO}_{4}$ layers grown (albeit unevenly) on baryte surfaces.

Barytes from experiment 6a-d also correlate to the models, with similarly low $S(x)$ and $J(x)$ values for sulfatefree environments and significantly higher $S(x)$ and $J(x)$ values in sulfuric acid solutions. Correspondingly, thick zones of Sr-rich sulfate can be seen on baryte surfaces in Fig. 3d.

Celestite models behaved somewhat differently from baryte, although similarities can be seen between the high-sulfate $(\mathrm{Ba}, \mathrm{Sr}) \mathrm{SO}_{4}$ trends and $(\mathrm{Sr}, \mathrm{Ba}) \mathrm{SO}_{4}$ trends. With exposure to $\mathrm{BaCl}_{2}$, higher supersaturation functions occur for both solutions, both heavily favoring $\mathrm{BaSO}_{4}$. Nucleation rates are split, with sulfate-free solutions favoring $\mathrm{BaSO}_{4}$ precipitation and sulfuric acid solutions preferring $\mathrm{SrSO}_{4}$ precipitation. Experimentally, Ba remains low in celestite with $<1 \%$ (m.b.) being common although thin $\mathrm{BaSO}_{4}$-rich overgrowth zones are seen in Fig. 4c. Nucleation rates would suggest that in sulfaterich environments $\mathrm{SrSO}_{4}$ is more likely to precipitate than $\mathrm{BaSO}_{4}$, although some $\mathrm{Ba}$ uptake is inevitable providing there is some $\mathrm{Ba}^{2+}$ available. Opposite inclinations exist in sulfate-poor environments. The former is counter-intuitive considering the higher solubility of celestite, but is confirmed experimentally by the presence of an irregular $\mathrm{BaSO}_{4}$ layer on the celestite surface in Fig. $4 \mathrm{c}-$ and the complete lack of the same in Fig. 4b, d, with the minimal $\mathrm{Ba}$ signal in the latter being due to diffusion, rather than an overgrowth of $\mathrm{BaSO}_{4}$.

Lead and $\mathrm{Sr}$ sulfate have similar solubility products; therefore, it is expected that nucleation rates will be similar. Celestite exposed to $\mathrm{PbCl}_{2}$ solution exhibits favorability towards $\mathrm{PbSO}_{4}$ in both the $S(x)$ and $J(x)$ functions, but the addition of $\mathrm{H}_{2} \mathrm{SO}_{4}$ not only greatly increases the nucleation rate but also shifts the $J(x)$ maximum from pure $\mathrm{PbSO}_{4}$ to a more predictable $\mathrm{X}_{\mathrm{PbSO} 4}=\mathrm{X}_{\mathrm{SrSO} 4}$. Figure 5 c clearly shows a few microns of $\mathrm{PbSO}_{4}$ overgrowth on the celestite surface, although the same cannot be 
seen in Fig. 5a. Pb uptake by celestite in sulfate solutions seems to remain low, although there are a few $\mathrm{PbSO}_{4}$ particles on the crystal surface in Fig. $5 \mathrm{~d}$. These are likely to be precipitates from the initial solution mixing which became lodged in the porous surface of the celestite, as no layering or adhesion to the surface is apparent.

Not surprisingly, $S(x)$ and $J(x)$ trends for the $(\mathrm{Pb}, \mathrm{Sr}) \mathrm{SO}_{4}$ system is similar to the $(\mathrm{Sr}, \mathrm{Pb}) \mathrm{SO}_{4}$ system. With less $\mathrm{Pb}^{2+}$ available, the $S(x)$ and $J(x)$ values for the Pb endmembers have been reduced to nearly zero in the sulfate-free solution. $S(x)_{\max }$ and $J(x)_{\max }$ in sulfuric acid solution remain the same, at $\mathrm{X}_{\mathrm{PbSO} 4} \approx 0.8$ and 0.5 , respectively, although the nucleation rate is somewhat reduced. From the LAICP-MS data, it can be seen that $\mathrm{Sr}^{2+}$ uptake by anglesite occurs in both systems, but different mechanisms may be responsible depending on $\mathrm{SO}_{4}{ }^{2-}$ availability. [Sr] seems stable at $10 \mathrm{wt} \%$ in all four crystals in Fig. $6 \mathrm{a}-\mathrm{d}$, but the sulfate-free samples show little to no surface alteration in the BSE images, whereas the sulfuric acid samples are clearly altered in zones up to $30 \mu \mathrm{m}$ thick. The simplest explanation is that-despite very low nucleation rates-very thin zones of high-Sr sulfate is forming on anglesite in sulfate-free solutions (overgrowth), whereas thick, porous zones of mixed $\mathrm{Pb}, \mathrm{Sr}$ sulfates are replacing anglesite in sulfate-rich solutions (CDR).

Keeping with the trend, $S(x)$ and $J(x)$ curves for $(\mathrm{Ba}, \mathrm{Pb})$ $\mathrm{SO}_{4}$ are similar to those for $(\mathrm{Pb}, \mathrm{Ba}) \mathrm{SO}_{4}$. Although supersaturation seems to favor $\mathrm{BaSO}_{4}$ precipitation, nucleation rates suggest nearly pure $\mathrm{PbSO}_{4}$ will occur instead. This effect presents as thick layers of $\mathrm{PbSO}_{4}$ on baryte but exhibits as a lack of any precipitation (or a reprecipitation of $\mathrm{Ba}$-doped $\mathrm{PbSO}_{4}$ ) on anglesite. Little to no $\mathrm{Ba}$ is present in the crystals shown in Fig. 7a, c, achieving only $1 \mathrm{wt} \%$ in very thin zones not visible in BSE images. With $\mathrm{H}_{2} \mathrm{SO}_{4}$, there is clearly a CDR reaction occurring, but the precipitation rate seems to be lagging significantly behind the dissolution rate. Porosity is very high, with most of the sparse replacement sulfate being $\mathrm{Pb}$-dominant.

These are obviously simplified models and although nucleation rate predictions seem to parallel experimental results there are other factors to consider. Chloride complexation amplifies $\mathrm{Sr}-$, $\mathrm{Ba}-$, and $\mathrm{PbSO}_{4}$ solubilities by many orders of magnitude, and are only passively included in the kinetics calculations in the form of sulfate solubility estimates in $\mathrm{Cl}^{-}$solutions. It is also well known that both thermodynamic and kinetic properties tend to diverge between bulk systems and nanoscale structures such as fractures [41, 42], pores [28], and ultrathin fluidsolid reaction interfaces [1].

\section{Leaching/recrystallization in experiments involving multiple sulfates Experimental results}

Most of the crystals from experiment 1 (neutral sulfate solution) were still clear and euhedral after the experiment. One $\mathrm{PbSO}_{4}$ crystal suffered damage during removal from the vial which resulted in a detrital coating on the undamaged $\mathrm{PbSO}_{4}$ crystal, visible in the BSE image. Figure 8 shows BSE images of the crystals (top) as well as color composites of the ${ }^{88} \mathrm{Sr},{ }^{138} \mathrm{Ba}$, and ${ }^{206} \mathrm{~Pb}$ nanoSIMS distribution maps overlying zoomed-in sections of the BSE images (bottom). Red squares indicate the area of mapping. The crystals appear to be internally clean, although small amounts of $\mathrm{Pb}$ are seen filling nearedge gaps in both the $\mathrm{SrSO}_{4}$ and $\mathrm{BaSO}_{4}$ crystals. Small patches of $\mathrm{Ba}$ can be seen within a few microns of the edge of the $\mathrm{SrSO}_{4}$, and a trace amount of $\mathrm{Sr}$ can be seen on the inside edge of the left crystal of $\mathrm{BaSO}_{4}$ (appears as orange). Virtually no $\mathrm{Sr}$ or $\mathrm{Ba}$ was detected in or on the surface of the $\mathrm{PbSO}_{4}$.

Figure 9 shows the resulting crystals from experiment 2 (acidic sulfate solution). These crystals were also in very good condition visually, although the normally transparent $\mathrm{PbSO}_{4}$ had become translucent. The $\mathrm{BaSO}_{4}$ crystal shattered during polishing. BSE images show a thin veneer of overgrowth on all three crystals, consisting of the other two sulfates. NanoSIMS images confirm this, and clearly show a thin $(<2 \mu \mathrm{m})$ layer of recrystallization. A comparison of signal intensities of the rim on $\mathrm{SrSO}_{4}$ produces an estimated $\mathrm{Sr}: \mathrm{Ba}: \mathrm{Pb}$ ratio of $15: 1: 10$; for the $\mathrm{BaSO}_{4}$ rim the ratio is $4: 6: 9$; for the $\mathrm{PbSO}_{4}$ rim the ratio is $8: 11: 2$.

The $\mathrm{BaSO}_{4}$ and $\mathrm{PbSO}_{4}$ crystals from experiment 3 (neutral chloride solution) were noticeably corroded and opaque, and thin layers of overgrowth could be seen flaking off even under low magnification. $\mathrm{SrSO}_{4}$ appears to have survived quite well, although surface pitting was visible under magnification. BSE images (Fig. 10) show some etching of $\mathrm{BaSO}_{4}$ and significant dissolution of $\mathrm{PbSO}_{4}$. NanoSIMS mapping revealed very little recrystallization on the $\mathrm{SrSO}_{4}$ and $\mathrm{PbSO}_{4}$ but showed what appeared to be $\mathrm{Sr}$ diffusion up to $\sim 6 \mu \mathrm{m}$ into the $\mathrm{BaSO}_{4}$ crystal with a thin, pure $\mathrm{PbSO}_{4}$ layer on the surface.

The surviving crystals from experiment 4 (acid chloride solution) were significantly corroded and opaque. No $\mathrm{BaSO}_{4}$ crystals were found, having presumably complexed with excess chloride and dissolved. NanoSIMS maps show little to no deposition on the surface of the corroded $\mathrm{SrSO}_{4}$, but the $\mathrm{PbSO}_{4}$ shows significant dissolution and replacement by both $\mathrm{BaSO}_{4}$ and $\mathrm{SrSO}_{4}$. Despite extensive $\mathrm{Pb}$ removal, the crystal clearly retained its original shape and the $\mathrm{PbSO}_{4}$ core remains intact. Figure 11 illustrates the extent of replacement, as the original 

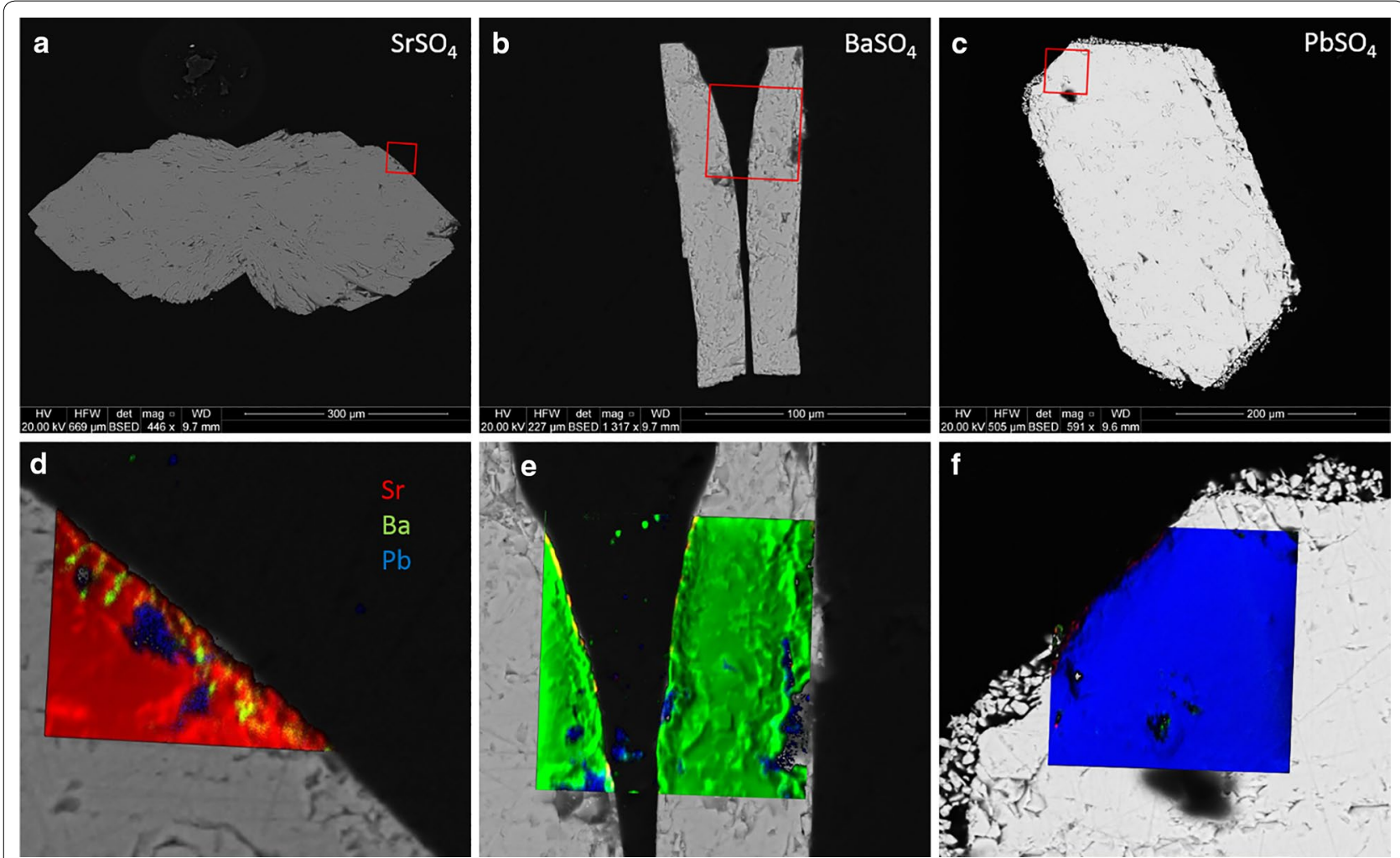

Fig. 8 BSE (a-c) and nanoSIMS overlays (d-f) of crystals exposed to neutral sulfate solution (vial 1). Sr $=r e d, B a=g r e e n, P b=b l u e$

$\mathrm{PbSO}_{4}$ (blue) is virtually gone with $\mathrm{Sr}$ (red) nearly completely replacing $\mathrm{Pb}$, and imported $\mathrm{Ba}$ (green, but displays as yellow-orange where overlapping red color) highlighting the edges of exposed surfaces.

Figure 12 contains a montage of 18 nanoSIMS images of the same grain, B4. The extent of Sr replacement is evident, as is the remaining untouched core of pure $\mathrm{PbSO}_{4}$. A remnant strip of $\mathrm{PbSO}_{4}$ can also be seen near the left edge of the grain (circled). The inset image shows detail of the boundary between the original $\mathrm{PbSO}_{4}$ and invasive Sr. Despite appearances, regions of $\mathrm{Sr}$ replacement still contain lead, and semi-quantification shows this material to be close to 3:1 in $\mathrm{Sr}: \mathrm{Pb}$. The 3:1 ratio holds for replacement regions near the edge as well as in the interior of the crystal. Similar analyses of blue regions reveal nearly pure $\mathrm{PbSO}_{4}$, with $\mathrm{Pb}: \mathrm{Sr}$ being $>100$. Figure 13 shows a small area of grain B4, with BSE (a), color-composite map (b), and $\log$-scale distribution map of $\mathrm{Pb}: \mathrm{Sr}$ (c). Although the color composite seems to indicate great variation in composition, the $\mathrm{Pb}: \mathrm{Sr}$ map shows that there are primarily three distinct classifications: high- $\mathrm{Pb}$ (red to white); high$\mathrm{Sr}$, low-Pb (blue); and epoxy (black). Boundaries between the relatively pure $\mathrm{PbSO}_{4}$ regions and the $\mathrm{Sr}: \mathrm{Pb} \approx 3$ regions are quite sharp, and the thin green perimeters are likely to be a result of a relatively large beam width $(\sim 400 \mathrm{~nm})$ compared to pixel size $(\sim 100 \mathrm{~nm})$ and not true gradients. Barium contribution is minimal, with the brightest area on the image representing only about $25 \%$ Ba content (total cations).

Figure 14 contains $\mathrm{Sr}: \mathrm{Ba}: \mathrm{Pb}$ ratios (in wt\%, normalized to $100 \%$ ) for 225 point analyses of nanoSIMS data from throughout the composite image in Fig. 12. Three classifications appear here, as well, with most of the points clustering around a rough composition of $\mathrm{Sr}_{3} \mathrm{~Pb}\left(\mathrm{SO}_{4}\right)_{4}$. A second cluster represents samples of nearly pure lead sulfate, with some samples trailing into the "Sr-bearing" zone. Again, this is quite possibly due to beam-width overlap as the true boundaries appear to be distinct and sharp. The third classification of points represents areas containing $>5 \% \mathrm{Ba}$, found almost exclusively near exposed surfaces. These regions likely crystallized last and contain mostly $\mathrm{SrSO}_{4}$ but may contain up to $55 \%$ $(\mathrm{Pb}+\mathrm{Ba}) \mathrm{SO}_{4}$.

\section{Interpretation and discussion}

The results shown in Fig. 8 (experiments containing neutral sulfate solution), are no surprise. Of the entire periodic table, only $\mathrm{Ba}, \mathrm{Ca}, \mathrm{Pb}, \mathrm{Ra}$, and $\mathrm{Sr}$ form insoluble sulfates in their most common oxidation state, with 

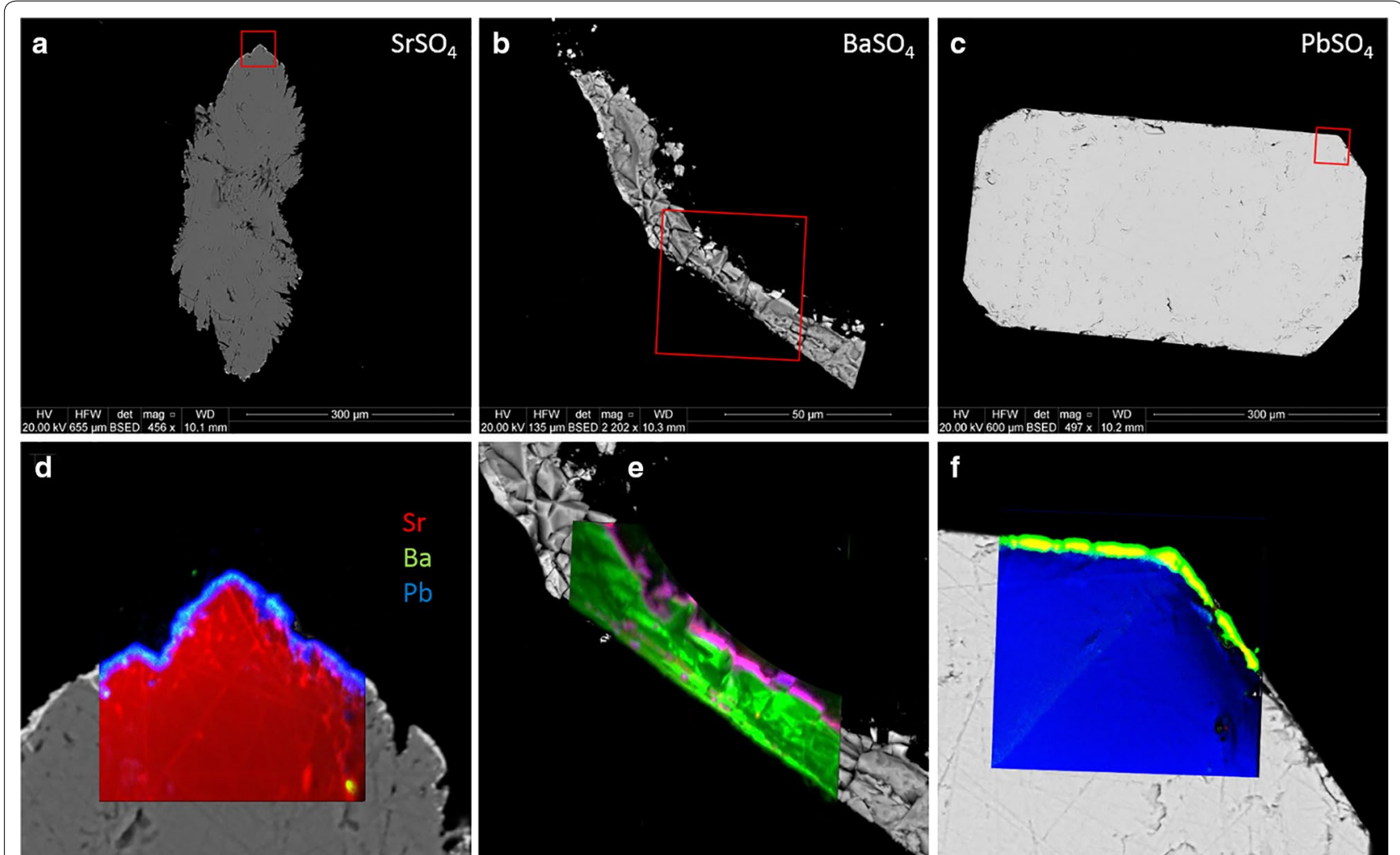

Fig. 9 BSE (a-c) and nanoSIMS overlays (d-f) of crystals exposed to acid sulfate solution (vial 2). $\mathrm{Sr}=\mathrm{red}, \mathrm{Ba}=\mathrm{green}, \mathrm{Pb}=$ blue. The thin magenta edge in (e) indicates $\mathrm{Sr}-\mathrm{Pb}$ overlap

minor species including $\mathrm{Hg}^{+}, \mathrm{Ag}^{+}$, and $\mathrm{Po}^{4+}$ [11]. The lack of available $\mathrm{H}^{+}$and of any complexing agent results in low activity and therefore virtually no mobility, with the compounds' solubility in water being the effective limiting factors. For a $200 \mu \mathrm{g}$ sample, the most soluble of these, $\mathrm{SrSO}_{4}$, should only lose a maximum of $3 \%$ to dissolution at $60^{\circ} \mathrm{C}$.

In Fig. 9, crystals from experiment $2(0.08 \mathrm{M}$ acid sulfate solution) show increased surface activity, with movement between all three compounds. A thin veneer of overgrowth $<2 \mu \mathrm{m}$ thick can be seen in the BSE images, especially around the $\mathrm{SrSO}_{4}$. Slight pitting and etching can also be seen, although this does not penetrate the crystal surfaces more than a micron or two. NanoSIMS images confirm that a thin layer of $(\mathrm{Sr}, \mathrm{Ba}, \mathrm{Pb}) \mathrm{SO}_{4}$ has deposited on the surface of all three crystals, although the $\mathrm{Sr}: \mathrm{Ba}: \mathrm{Pb}$ ratio differs between the three. From these ratios, it appears that $\mathrm{Sr}$ mostly either precipitates back on the $\mathrm{SrSO}_{4}$ as a mixed $\mathrm{Sr}-\mathrm{Pb}$ sulfate, with little $\mathrm{Ba}$, or it precipitates on the $\mathrm{PbSO}_{4}$ as a $\mathrm{Sr}$-Ba mixed sulfate, with very little $\mathrm{Pb}$. Lead mobility seems to be one-directional, with liberated $\mathrm{Pb}^{2+}$ preferring to recrystallize on the other two sulfates but not back on the $\mathrm{PbSO}_{4}$.
LA-ICP-MS results seem to differ here from the nanoSIMS maps, with thin overgrowths evident in experiments 1-4 but only on both barytes and one anglesite in the simple reaction experiments. Although both sets of experiments were under acid sulfate conditions, those in the simple reaction experiments also contained significant chloride from the added $0.1 \mathrm{M} \mathrm{MCl}_{2}$ solutions. In effect, experiment 2 contained only $\mathrm{H}_{2} \mathrm{SO}_{4}$ whereas the "b" and "d" sub-set of experiments 5 through 10 contained $\left[\mathrm{H}^{+}\right]+\left[\mathrm{SO}_{4}{ }^{2-}\right]+\left[\mathrm{Cl}^{-}\right]$. Chloride is well known as a strong complexing agent with $\mathrm{Sr}, \mathrm{Ba}$, and $\mathrm{Pb}$ which appears to have subdued the formation of overgrowth layers in some cases, especially on celestite.

Results for crystals of $\mathrm{BaSO}_{4}$ and $\mathrm{PbSO}_{4}$ in Fig. 10 from experiment 3 (0.1 M neutral chloride solution) were similarly unsurprising, as it is well known that alkali earths and lead form soluble chloride complexes. Visible etching of the $\mathrm{SrSO}_{4}$ was surprisingly low, however Lucchesi and Whitney [20] show that for $<1 \mathrm{M} \mathrm{NaCl}$, solubility of $\mathrm{SrSO}_{4}$ decreases with temperature, with values of $185 \mathrm{mg} / \mathrm{L}$ at $0{ }^{\circ} \mathrm{C}$ and $170 \mathrm{mg} / \mathrm{L}$ at $25^{\circ} \mathrm{C}$. An estimate of $150 \mathrm{mg} / \mathrm{L}$ for $60{ }^{\circ} \mathrm{C}$ would result in $<4 \%$ solubility for a $200 \mu \mathrm{g}$ sample. The $\mathrm{BaSO}_{4}$ shows noticeable etching and pitting on the surface. The small amount of $\mathrm{Sr}^{2+}$ liberated 

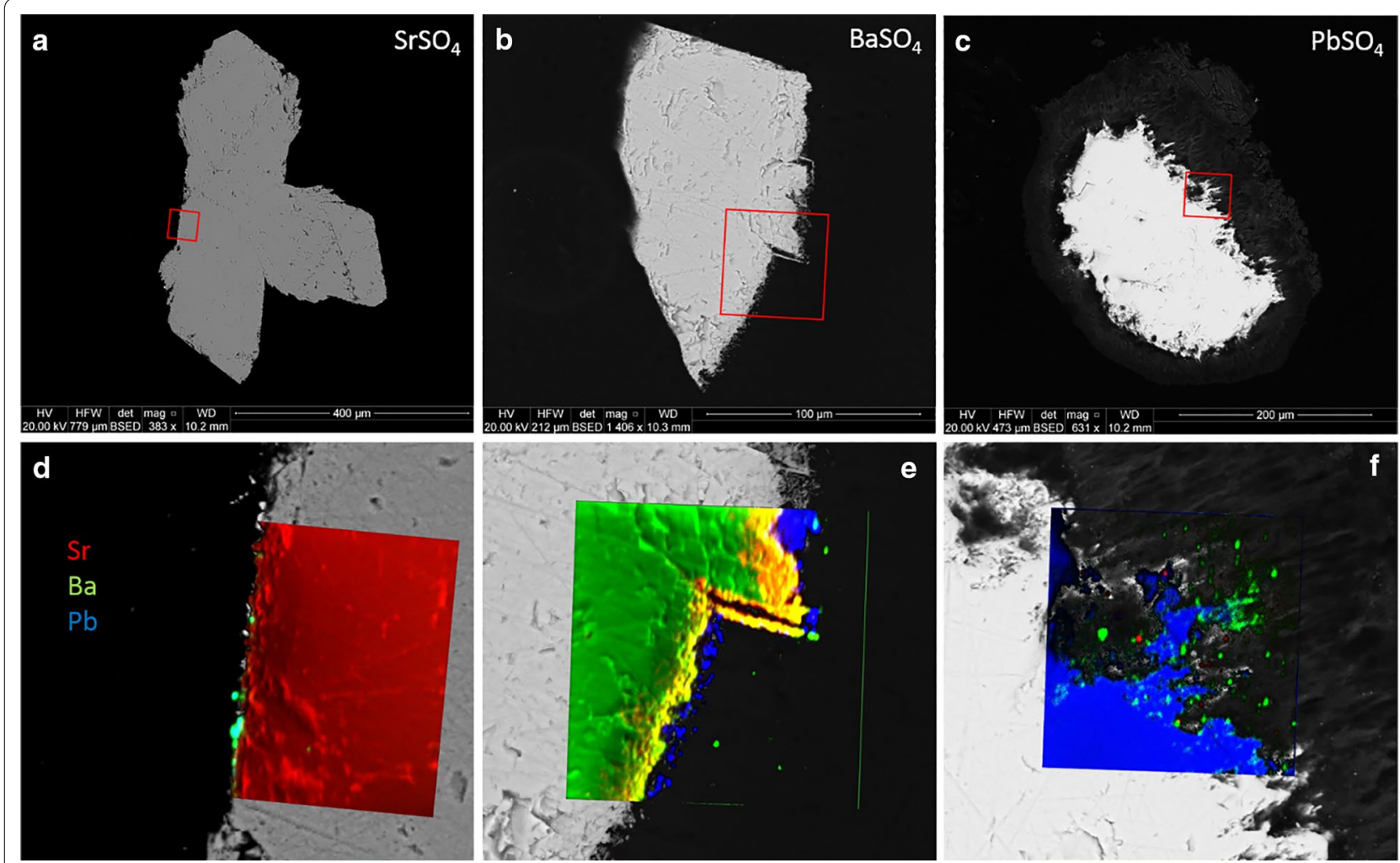

Fig. $10 \mathrm{BSE}(\mathbf{a}-\mathbf{c})$ and nanoSIMS overlays (d-f) of crystals exposed to neutral chloride solution (vial 3). $\mathrm{Sr}=\mathrm{red}, \mathrm{Ba}=\mathrm{green}, \mathrm{Pb}=\mathrm{blue}$. The yellow-orange band in (e) denotes Sr-Ba overlap

seems to have ended up entirely in the $\mathrm{BaSO}_{4}$, appearing as a diffuse boundary extending up to $6 \mu \mathrm{m}$ in from the surface. Although a substantial amount of $\mathrm{Ba}^{2+}$ has been liberated from the sulfate, none of this is found in the $\mathrm{SrSO}_{4}$-although a few tiny blebs can be seen on the surface. With crystal ionic radii (CIR) of $1.58 \AA$ for $\mathrm{Sr}^{2+}$ and $1.75 \AA$ for $\mathrm{Ba}^{2+}$ [39], it makes sense that $\mathrm{BaSO}_{4}$ could incorporate $\mathrm{Sr}^{2+}$ while $\mathrm{SrSO}_{4}$ would not accommodate the larger $\mathrm{Ba}^{2+} . \mathrm{Pb}^{2+}$ is very similar in size to $\mathrm{Sr}^{2+}$, having a CIR of $1.63 \AA$ (ibid.). There is a thin, patchy layer of pure $\mathrm{PbSO}_{4}$ on the surface of the $\mathrm{BaSO}_{4}$. It is logical that most of the $\mathrm{Pb}$ and $\mathrm{Ba}$ liberated by complexation with chloride remained in solution and was rinsed away when the crystals were washed.

Laser ablation results from the "a" and "c" sub-sets of experiments (also neutral chloride conditions) expand on these results. Thin $\mathrm{Ba}$ and $\mathrm{Pb}$ overgrowth layers are seen on celestite but only in the 210-h experiments, indicating sluggish kinetics. Baryte crystals showed little uptake of either $\mathrm{Sr}$ or $\mathrm{Pb}$, but independent spots did reach $1 \mathrm{wt} \%$ in both cases. Anglesite showed an affinity towards Sr, incorporating over 100,000 ppm in thin edge zones. This was not apparent from the nanoSIMS results, the primary difference being that the only source of $\mathrm{Sr}^{2+}$ in that experiment was the $\mathrm{SrSO}_{4}$ crystal itself-which showed virtually no signs of dissolution. When $\mathrm{Sr}^{2+}$ is in great excess, however, anglesite readily accommodates thin Srrich overgrowth layers. Barium uptake in anglesite is negligible with $\mathrm{Ba}: \mathrm{Pb}$ never exceeding 0.25, and then only in sub-micron patchy layers.

Experiment 4 (0.12 $\mathrm{M}$ acid chloride solution) gave the most impressive results. $\mathrm{BaSO}_{4}$ had completely complexed with chloride and was removed with the rinse. This was surprising considering the relatively moderate removal of $\mathrm{BaSO}_{4}$ in the neutral chloride solution. Little work has been done comparing neutral vs. acidic solutions of the same anion, but Lucchesi and Whitney [20] show for $\mathrm{SrSO}_{4}$ that $\mathrm{pH}$ has little effect on solubility in sulfate solutions but that $\mathrm{HCl}$ can dissolve 3-3.5 times as much $\mathrm{SrSO}_{4}$ as similar concentrations of $\mathrm{NaCl}$. For baryte, the $\mathrm{K}_{\mathrm{sp}}$ would have to increase by more than 3 orders of magnitude to account for complete removal. The crystal ionic radius of $\mathrm{Ba}^{2+}$ would prevent diffusive uptake into either $\mathrm{PbSO}_{4}$ or $\mathrm{SrSO}_{4}$, although some late-stage replacement (co-crystallization with $\mathrm{Sr}$ ) of $\mathrm{PbSO}_{4}$ seems apparent from the nanoSIMS images.

Liberated $\mathrm{Sr}^{2+}$ appears to have predominantly replaced $\mathrm{Pb}^{2+}$ in the $\mathrm{PbSO}_{4}$ crystal. Thin $\mathrm{BaSO}_{4}$-rich 

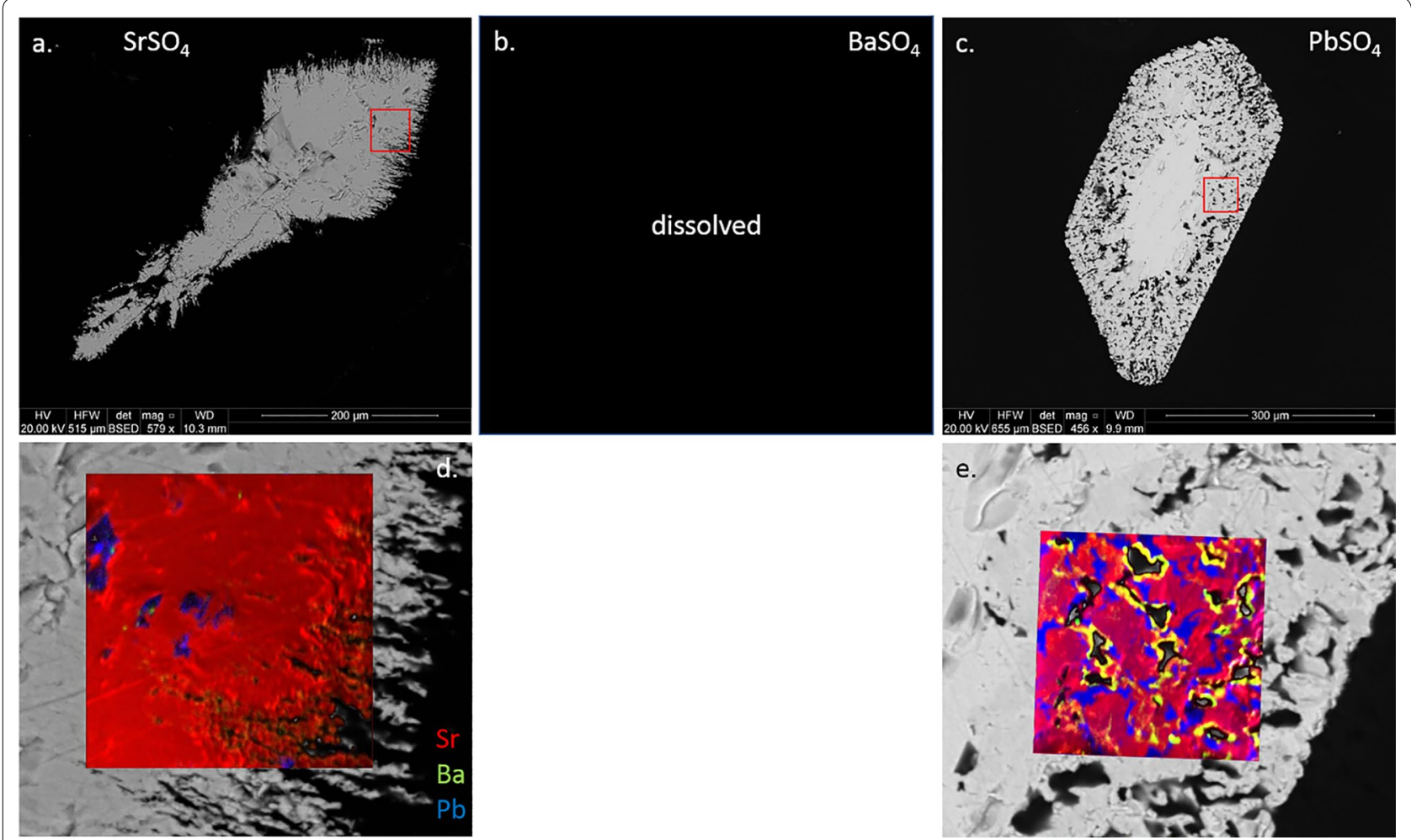

Fig. 11 BSE (a-c) and nanoSIMS overlays (d-e) of crystals exposed to acid chloride solution (vial 4). Sr=red, Ba=green, Pb = blue. The yellow edging in (e) indicates Sr-Ba overlap

rims are found on most surfaces (Fig. 13b), indicating either a local (fluid-crystal interface) or "global" increase in $\left[\mathrm{Ba}^{2+}\right] /\left(\left[\mathrm{Pb}^{2+}\right]+\left[\mathrm{Sr}^{2+}\right]\right)$. Local concentration gradients may exist due to a lack of convection, with interfacial fluid chemistry following different thermodynamic properties from bulk fluids [10, 15, 34]. Global concentration changes would imply precipitation of sufficient $\mathrm{Pb}$ and $\mathrm{Sr}$ from the overall solution to trigger favorable kinetics for $\mathrm{BaSO}_{4}$ (or at least Ba-rich sulfate) precipitation. Visible textures suggest coupled dissolution/ reprecipitation (CDR), a mechanism of pseudomorphic replacement $[26,27,30]$ with the possible end-result (if given sufficient time) being a celestite pseudomorph after anglesite. Future experiments will test this pathway further.

\section{Synthesis and comparison of results}

Laser ablation results from the "b" and "d" sub-set of experiments 5-10 show remarkably similar patterns to those in experiment 4-at least for celestite and anglesite. Incorporation of $\mathrm{Ba}$ and $\mathrm{Pb}$ into celestite is minimal, topping out at $1.2 \mathrm{wt} \%$ and $1.4 \mathrm{wt} \%$, respectively. Etching of surface material is visible. Baryte showed more uptake, with thick overgrowth layers of nearly pure $\mathrm{SrSO}_{4}(\mathrm{Sr}: \mathrm{Ba}$ approaching 7) and $\mathrm{PbSO}_{4}(\mathrm{~Pb}: \mathrm{Ba}$ surpassing 150). Baryte dissolution in experiment 4 is likely the result of that vial containing $\mathrm{HCl}$ with no added $\left(\mathrm{SO}_{4}{ }^{2-}\right)$, whereas experiments $5(\mathrm{~b}, \mathrm{~d})$ and $6(\mathrm{~b}, \mathrm{~d})$ contained $\mathrm{H}^{+}, \mathrm{Cl}^{-}$, and excess $\left(\mathrm{SO}_{4}{ }^{2-}\right)$. Excess sulfate will affect activity factors as well as inhibit dissolution, even in the presence of chloride. Anglesite once again showed the most impressive results, with thick, visible zones of dissolution and recrystallization in both $\mathrm{Sr}^{2+}$ and $\mathrm{Ba}^{2+}$ solutions. Although the $\mathrm{Sr}: \mathrm{Pb}$ did reach 2.7 on one edge, in agreement with the nanoSIMS results, most areas showed lower-but still significant-concentrations of Sr. This is likely due to excess sulfate in in the simple reaction experiments, while experiment 4 contained excess acid chloride only. Additionally, dissolution of all three was more significant in the multi-sulfate experiments for the same reason.

These results indicate there are three distinct mechanisms at work, depending on conditions: overgrowth, diffusion, and CDR. Overgrowth refers to the addition of crystalline sulfate on the surface of an existing crystal which has a different composition than the host. The pure $\mathrm{PbSO}_{4}$ layer on the surface of baryte in Fig. $2 \mathrm{~d}$ is an excellent example. In this case, the $\mathrm{BaSO}_{4}$ structure acts as a template for $\mathrm{PbSO}_{4}$ crystallization, but there appears to be no dissolution of baryte or significant incorporation of $\mathrm{Ba}^{2+}$ in the fresh $\mathrm{PbSO}_{4}$ layer. The morphology of the 


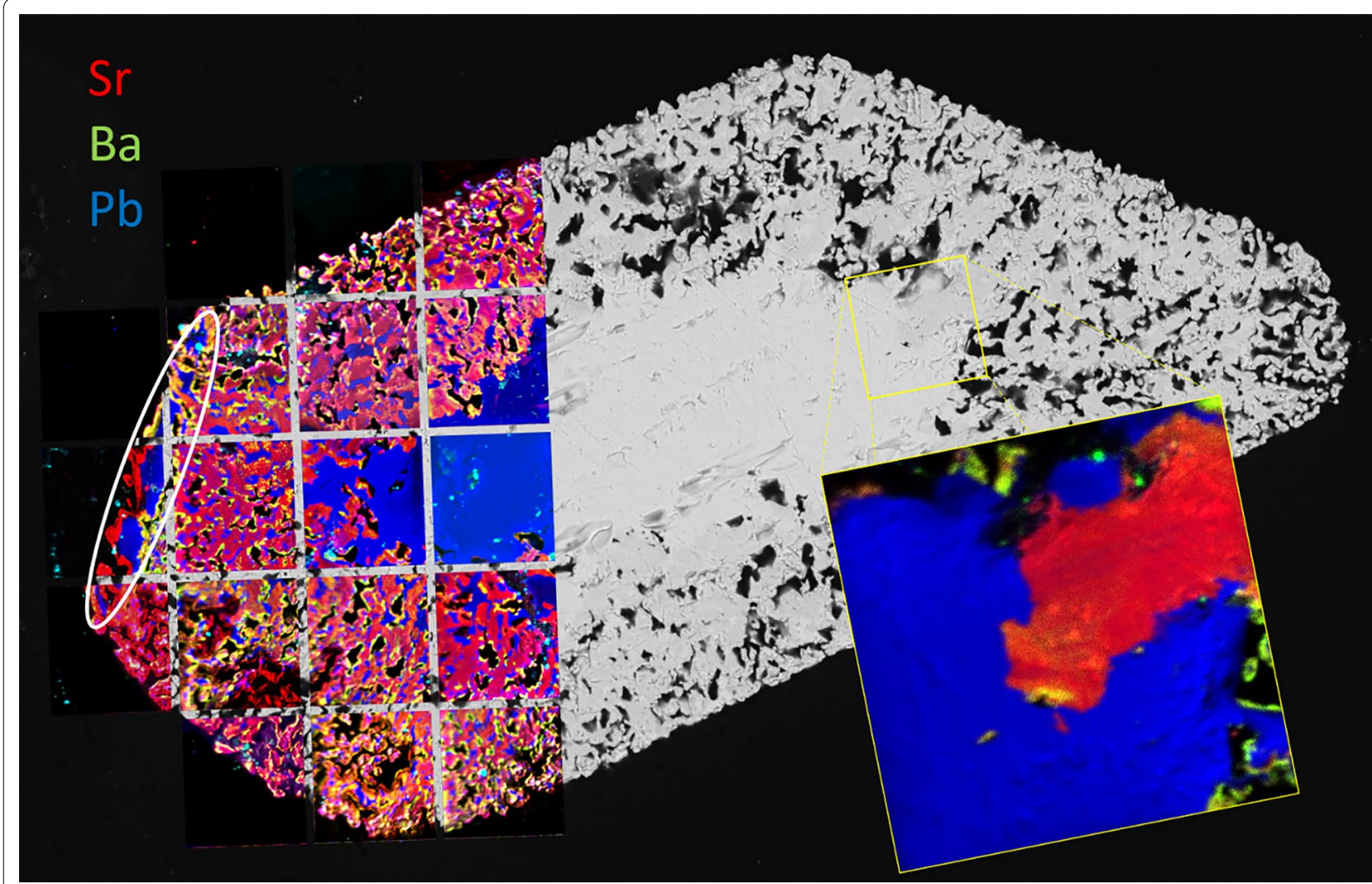

Fig. $12 \mathrm{BSE}$ image of $\mathrm{PbSO}_{4}$ grain B4, overlain with 19 tri-color composite nanoSIMS images. $\mathrm{Sr}=$ red, $\mathrm{Ba}=$ green, $\mathrm{Pb}=$ blue
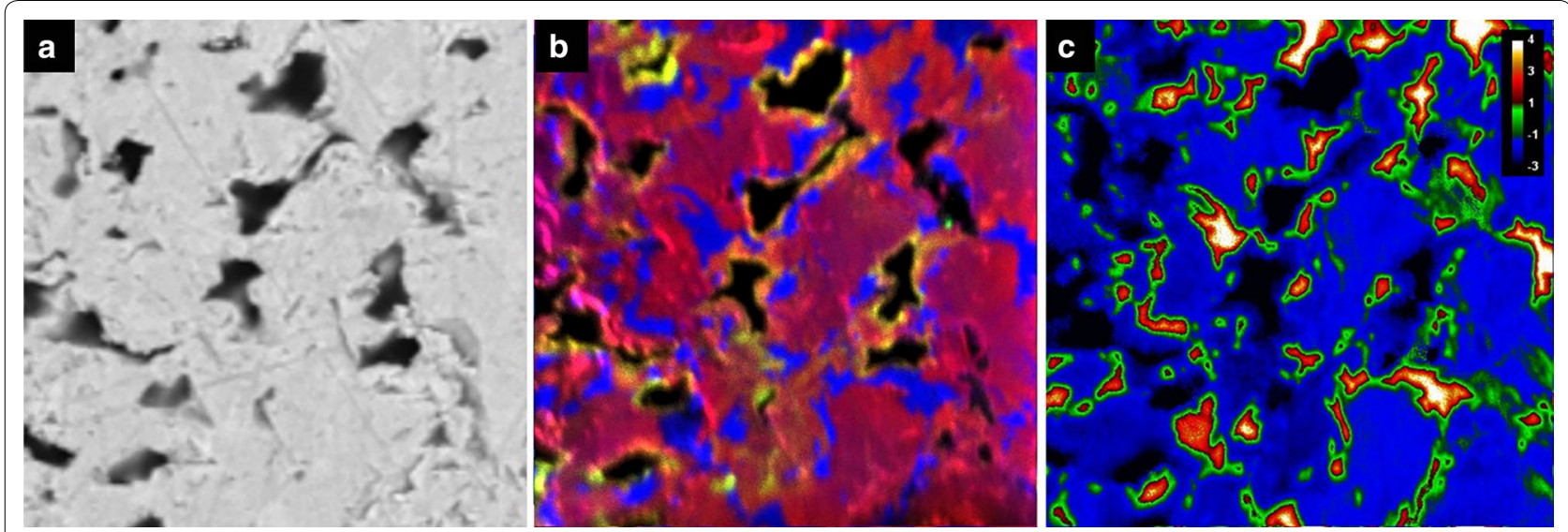

Fig. 13 Detail of a $50 \times 50 \mu \mathrm{m}$ area from $\mathrm{PbSO}_{4}$ grain $\mathrm{B} 4$, shown as a BSE image, $\mathbf{b}$ color composite ( $\left.\mathrm{Sr}=\mathrm{red}, \mathrm{Ba}=\mathrm{green}, \mathrm{Pb}=\mathrm{blue}\right)$, and $\mathbf{c}$ log Pb:Sr . The yellow edging in $\mathbf{b}$ represents $\mathrm{Sr}$-Ba overlap

parent crystal is not maintained, with the $\mathrm{PbSO}_{4}$ clearly a surficial addition. There is also no porosity visible in the $\mathrm{PbSO}_{4}$.

Diffusion exists when there is no visible change to the crystal surfaces, although low but measurable concentrations of contaminant elements are present near grain edges. Concentrations tend to decrease with increased depth, as implied in Fig. 15 (experiment 9d). Diffusion may be aided by porosity, as in Fig. 5c, or may be dictated by crystallographic orientation. It 


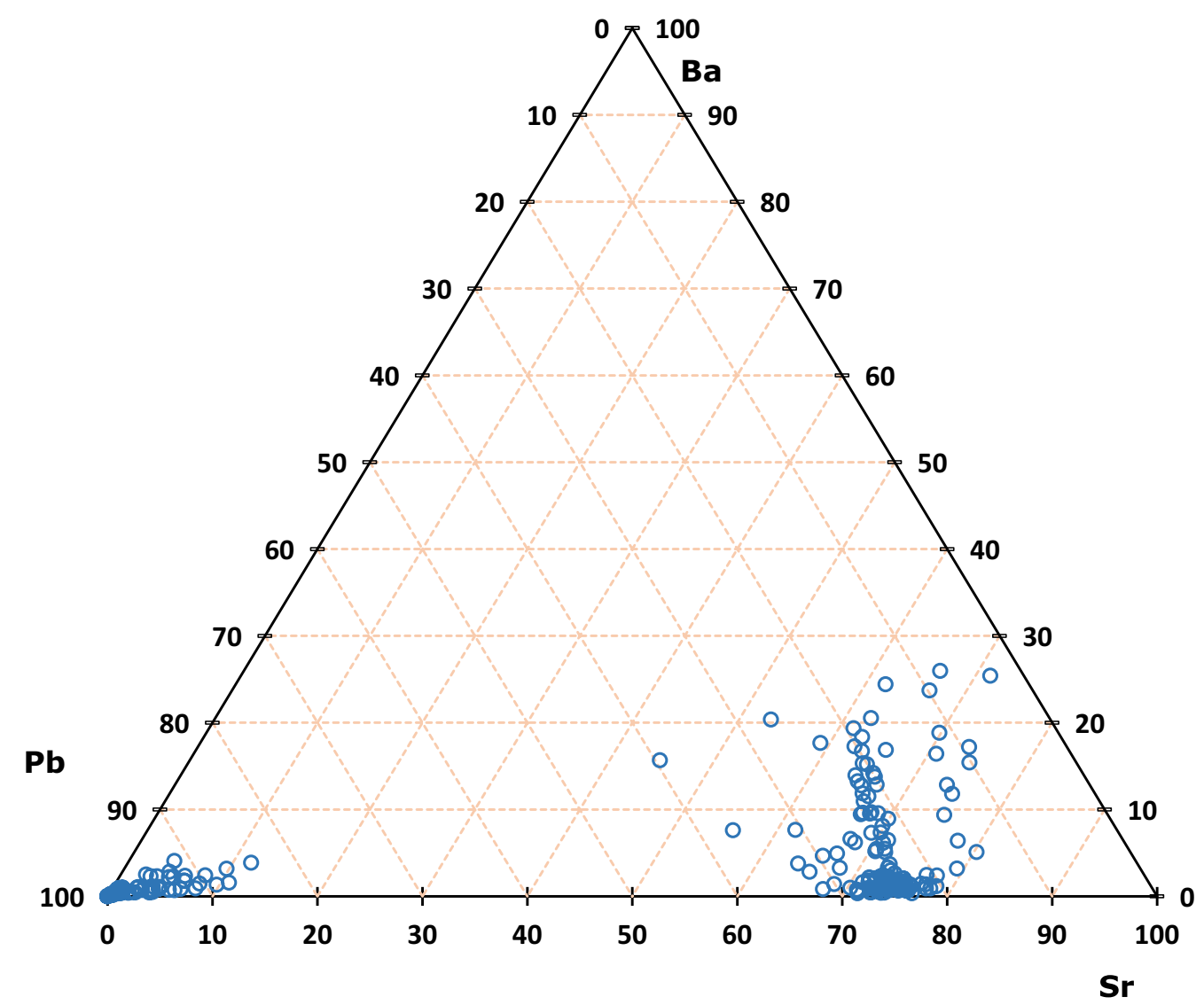

Fig. 14 Ternary Ba-Pb-Sr diagram of 225 nanoSIMS spot analyses from grain B4. Ba:Sr:Pb in wt\%, normalized to 100\%

is possible, however, for CDR to resemble diffusion, depending on the difference in dissolution and precipitation rates and the amount of resulting porosity. Putnis [26] states "Although volume diffusion is of course always operating, it is doubtful whether it plays a significant role when fluids are present and dissolutionprecipitation is another available mechanism". The key phrase in that statement is "significant role", although strong evidence exists for a diffusive mechanism. Figure 16 shows nanoSIMS results from a tangential experiment in which diffusion fronts can be seen mimicking crystallographic planes. Concentrations are low, however, and it is unlikely that diffusion (at only $60{ }^{\circ} \mathrm{C}$ ) was significant in these experiments or will be influential in any future $\left(\mathrm{Ra}^{2+}, \mathrm{Pb}^{2+}\right)$ removal scenarios.

CDR is a complex mechanism by which a dry-stable compound will undergo dissolution and replacement by an alternatively stable compound when exposed to fluids. Five criteria for identifying CDR have been suggested [27]:
1. Dissolution and precipitation fronts are spatially close. This is crucial for the preservation of morphology of the parent mineral.

2. Sharp reaction fronts dominate, with minimal evidence of solid-state diffusion fronts.

3. The recrystallization product is porous and permeable, allowing continuous fluid contact.

4. Fractures are common ahead of the reaction front, associated with a sufficient increase or decrease in molecular volume.

5. Epitaxial continuity exists across the reaction interface for dissolution/precipitation pairs with similar crystal structures. For dissimilar pairs, a polycrystalline product is observed.

Mineral pseudomorphs are classic examples of this [27, 30]. Figures 12 and 13 show a clear example of anglesite being replaced primarily by $(\mathrm{Sr}, \mathrm{Pb}) \mathrm{SO}_{4}$, with later $(\mathrm{Ba}$, $\mathrm{Sr}) \mathrm{SO}_{4}$. Data in Fig. 14 suggest temporary stability around $\mathrm{Sr}: \mathrm{Pb}=3$, although the system is clearly not in equilibrium. Reprecipitation lags slightly behind dissolution, with the resultant porosity exceeding 30\%-not 


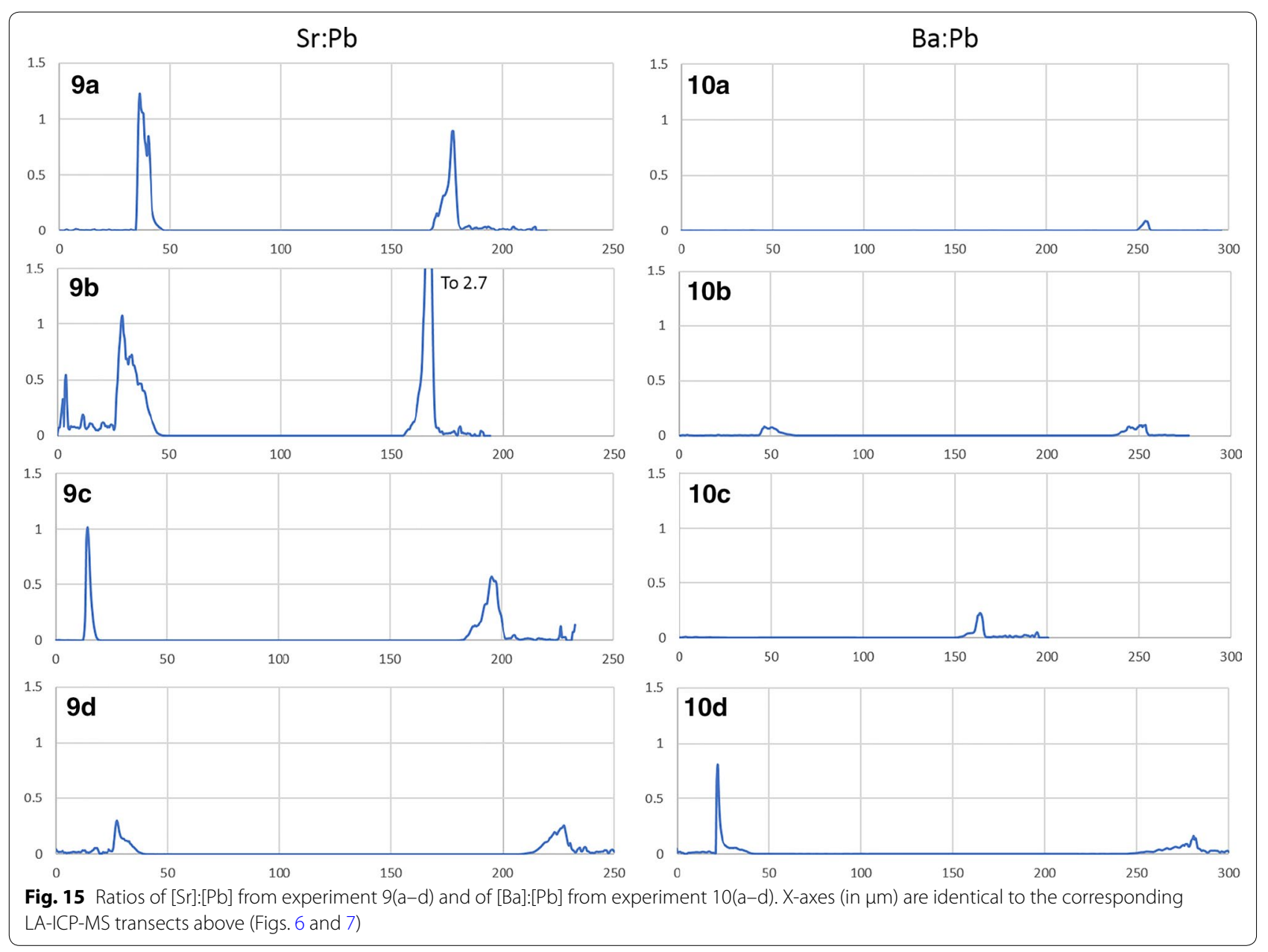

achievable by molecular volume difference alone. Figures $6 \mathrm{~b}, \mathrm{~d}$ and $7 \mathrm{~b}, \mathrm{~d}$ confirm these results. With $40 \mathrm{~h}$ of low $\mathrm{pH} \mathrm{SrCl} 2$ exposure (Fig. 6b), anglesite shows thick replacement zones on prismatic faces (parallel to $\mathrm{b}$ axis) consisting of roughly $\mathrm{PbSr}\left(\mathrm{SO}_{4}\right)_{2}$. After $210 \mathrm{~h}$ under the same conditions (Fig. 6d), the Sr:Pb dropped to 0.25 but the resulting patchy zones are up to 4 times thicker. Reprecipitation nearly matches dissolution, with porosity of only $10 \%$. Figure $7 \mathrm{~b}, \mathrm{~d}$ shows advanced dissolution rims, with $\mathrm{Ba}$-rich $\mathrm{PbSO}_{4}$ precipitation lagging. Porosity exceeds $85 \%$ at $40 \mathrm{~h}$ but is reduced to $70 \%$ at $210 \mathrm{~h}$, though the reaction zone has not increased in width. It has been suggested that dissolution and precipitation rates must be necessarily equal to maintain parent crystal morphology [26], yet these timed results suggest there may some room for inequality.

Figure 15 shows the $[\mathrm{Sr}] /[\mathrm{Pb}]$ for experiments $9(\mathrm{a}-\mathrm{d})$ and $[\mathrm{Ba}] /[\mathrm{Pb}]$ for experiments $10(\mathrm{a}-\mathrm{d})$. The difference between overgrowth and other uptake methods becomes clear, with thin, nearly pure layers of overgrowth presenting as sharp, symmetric peaks, as seen in the left grain edge of 9c. The right edge of grain 9c is shorter, wider, and asymmetric indicating either diffusion or CDR. Both grain edges of $9 \mathrm{~d}$ appear to be diffusion but are known to be CDR from textural observations, as are both edges of 10b. The left edge of grain 10d appears to be a hybrid, with a sharp overgrowth peak (or more likely a single particle of $\mathrm{BaSO}_{4}$ precipitate adhered to the grain surface) with a much lower concentration of Ba within the grain, decreasing to zero with depth. Naturally, grain orientation in the mount and angle of transect intercept will impart some bias to the shape and amplitude of these peaks, but these ratios can reveal features that are not obvious from transects alone. They emphasize, for example, the preference of Sr uptake over Ba uptake in anglesite.

Similar to diffusion, concentration of contaminants in CDR examples tends to be higher near the original grain surface and decrease with depth. As dissolution progresses, followed by reprecipitation of the new solution components on fresh surfaces, there will be an increase in concentration of the sulfate host cation and a decrease in concentration of the fluid cationic component. As the 

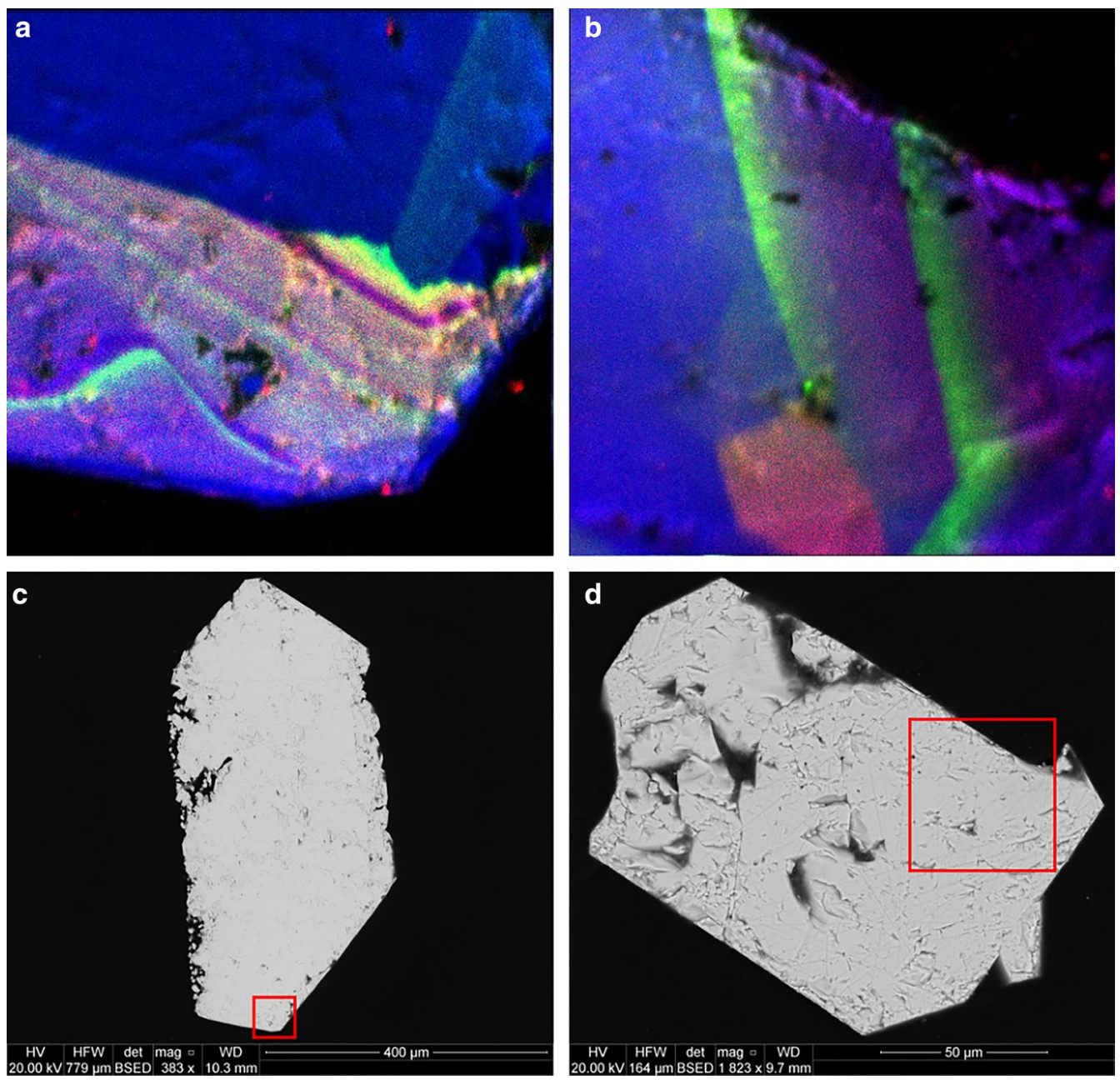

Fig. 16 NanoSIMS color composite images $(\mathbf{a}, \mathbf{b})$ and corresponding BSE images (c, d) of anglesite crystals. Red squares indicate $50 \times 50 \mu \mathrm{m}$ nanoSIMS mapped areas. Diffusion fronts of $\mathrm{Ba}$ ( $g r e e n)$ and $\mathrm{Sr}$ (red) can be clearly seen, apparently emulating crystallographic structures of the $\mathrm{PbSO}_{4}$ (blue)

reaction progresses deeper into the crystal, the solution composition will, to some extent, approach the host end member. This would not apply for well-mixed, endless reservoir systems, but for stagnant limited reservoir systems where diffusion kinetics outperform convection kinetics (as tested here) the effect is evident.

LA-ICP-MS transects show this, with both diffusion fronts and CDR reaction zones recognizable as decreasing product/parent cation ratios towards the center of the crystal (Fig. 15). The relatively large laser spot size, however, results in an averaging effect which swamps finer detail. NanoSIMS images (Figs. 12 and 13) show a general decrease in Ba concentration towards the center of the crystal on a large scale but reveal sharp reaction fronts at high resolution. For this example, four of the five criteria above are met with only $\Delta_{\mathrm{vol}}$-induced fracturing absent. In this case, fracturing would not be expected as the molecular volume of $\left(\mathrm{Sr}_{0.75} \mathrm{~Pb}_{0.25}\right) \mathrm{SO}_{4}$ is only $2.4 \%$ less than the molecular volume of $\mathrm{PbSO}_{4}$.

Porosity is not only a by-product but also a crucial component in CDR [34]. Anglesites in Figs. 6, 7, and 11, 12, 13 show classic CDR textures, similar to those in other published works (Figs. 1a-g and 10a, b in [34]. The rates at which crystals dissolve and reprecipitate (or more accurately, the difference between these rates) will determine not only their new composition, but also the homogeneity and depth of alteration. Based on these rates, minerals may dissolve completely, undergo partial alteration along surfaces and fractures, pseudomorph into an entirely new mineral, or be completely unaffected. Given enough time and preferential metasomatic conditions, mineral grains may be entirely replaced by new minerals with little trace remaining of the original grain other than its shape. Replacement mechanisms are varied, and parent/product 
compositions may be similar (azurite after malachite, goethite after hematite, etc.), or entirely different (petrified wood, pyrite after aragonite bivalve and gastropod shells; [2]. Judging from the porosity observed in these experiments, replacement of anglesite by celestite (or at least $\left.(\mathrm{Sr}, \mathrm{Pb}) \mathrm{SO}_{4}\right)$ was underway, and was interrupted upon conclusion of the experiment. The same cannot be said for baryte replacement of anglesite, as the porosity seems far too high to sustain complete regrowth. Molecular volume also must be considered, as it is much more difficult to substitute a $\mathrm{Ba}^{2+}(1.75 \AA)$ into a site normally held by $\mathrm{Pb}^{2+}(1.63 \AA)$, whereas swapping in a $\mathrm{Sr}^{2+}(1.58 \AA)$ would be energetically effortless. Porosity would therefore be critical in the incorporation of $\mathrm{Ba}$ into $\mathrm{PbSO}_{4}$, or $\mathrm{Ra}(1.84$ $\AA$ ) into any other sulfate, as the increase in molecular volume would necessarily have to be alleviated by pore spaces [34], or substitution pairing with smaller-radii ions (e.g. $\left.\mathrm{Mg}^{2+}, \mathrm{Ca}^{2+}\right)$. Crystal radii from [39]. From starting conditions, it should be possible to predict crystallization products based solely on thermodynamics, but kinetic effects profoundly complicate this. Figure 17 presents the models of all 12 ionic combinations (ignoring the reaction time aspect of the experiments).

\section{Processing implications}

Projecting the above results forward, controlling conditions to maximize replacement mechanisms may be the key for $\mathrm{Pb}$ and $\mathrm{Ra}$ removal from copper concentrates. Knowing the composition and abundance of non-economic minerals present in the concentrate, and the conditions of acid leaching and subsequent washing, it may be possible to construct a cationic replacement scenario targeting $\mathrm{Pb}$ or $\mathrm{Ra}$, or ideally all "insoluble" sulfates.

What sets this study apart from others is that previously, most solubility experiments were performed on isolated compounds. The benefits of this, of course, were simpler data analysis and more accurate data. What was missed, however, was the potential for seeing movement between compounds-with no corresponding increase or decrease in overall solubility. With simplistic experiments, it may be assumed that once $\mathrm{Sr}^{2+}, \mathrm{Ba}^{2+}$, or $\mathrm{Pb}^{2+}$ ends up in solution, an equilibrium state is met. Once this occurs, the same concentration of ions remains in solution, and is removed during rinsing. During the experiment, liberated ions have nowhere to go other than recrystallizing back on the crystal or remaining in solution. Multiple phases, however, result in multiple potentials which may manifest as mobility between phases (reduction in entropy) with no change in ionic strength of the solution. NanoSIMS images show that there is significant potential for movement between sulfates although solubilities remain low; LA-ICP-MS transects support this hypothesis.

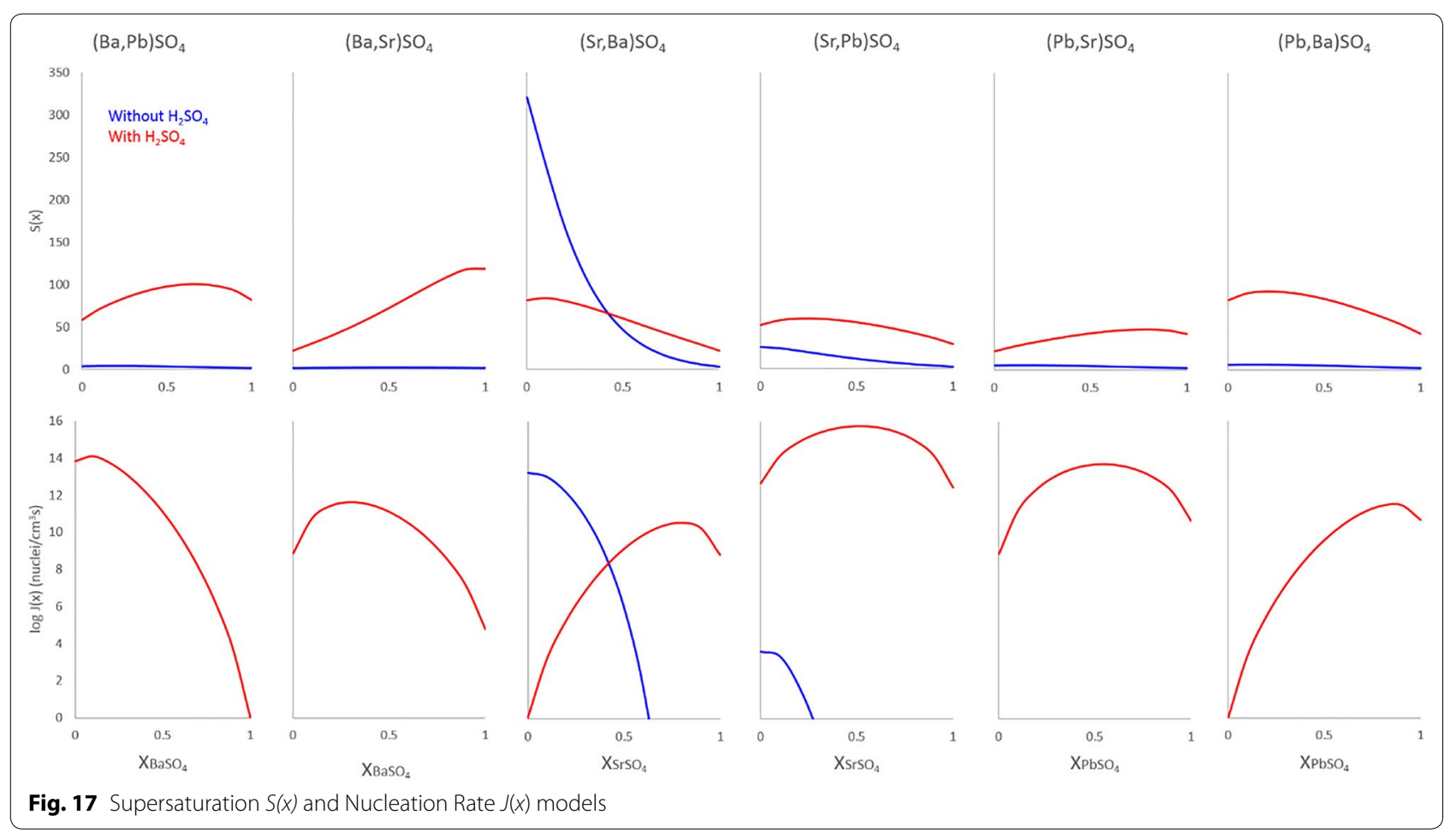



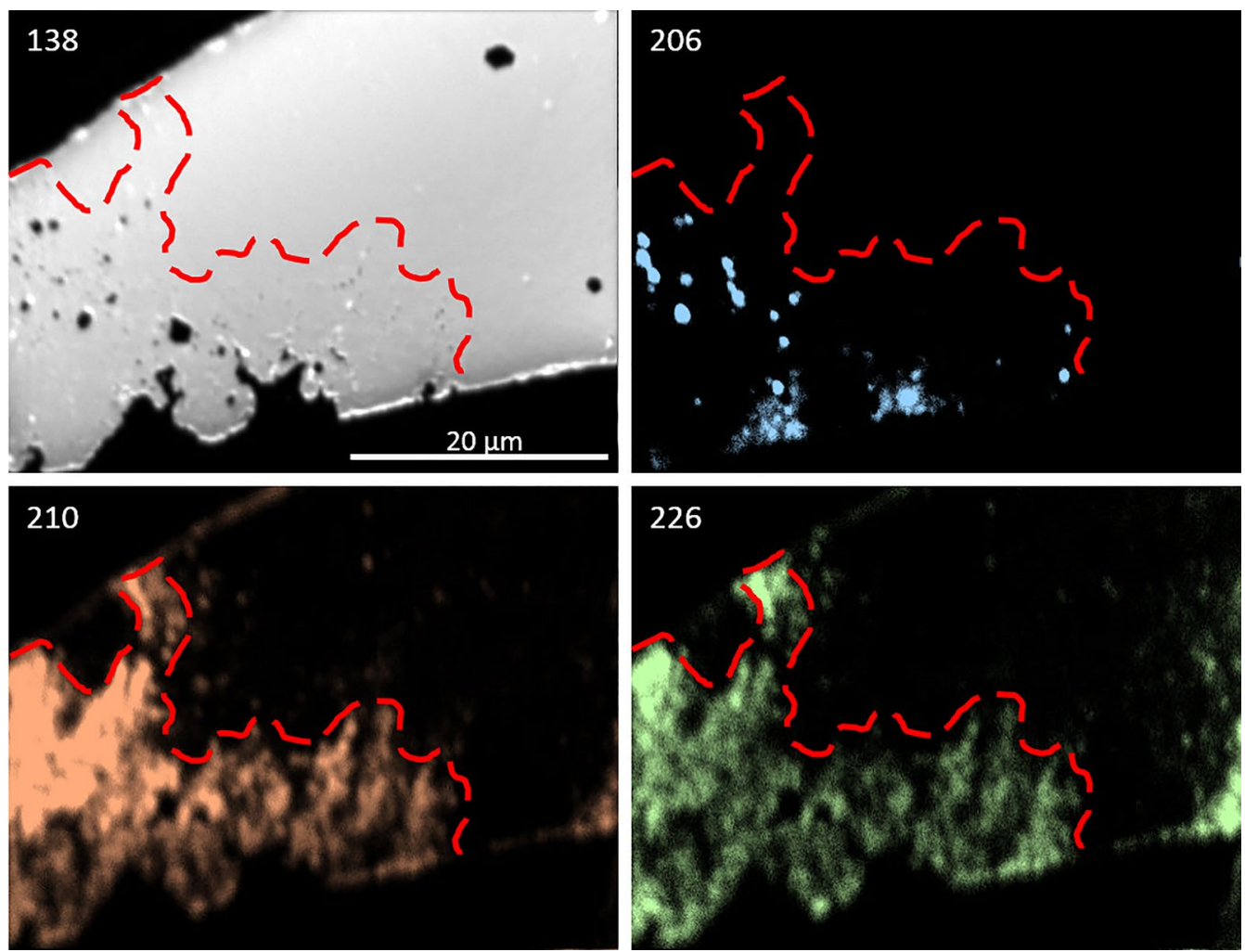

Fig. 18 NanoSIMS images of baryte in leached concentrate sample 05CLD 13 from Olympic Dam. The estimated reaction front is marked in red. The non-correlation between ${ }^{206} \mathrm{~Pb}$ and ${ }^{210} \mathrm{~Pb}$ indicate multiple pathways; coeval incorporation of old lead into the baryte, uptake of ${ }^{210} \mathrm{~Pb}$ by the baryte during acid-leaching, and decay of ${ }^{210} \mathrm{~Pb}$ from ${ }^{226}$ Ra previously taken in by the baryte

Given these results, the question arises: how would they apply to real-world examples? The purpose of this research is to find a practical and efficient pathway for the removal of Ra and lead-210 from copper concentrates. Celestite and anglesite are rare in Olympic Dam ore, although some replacement $\mathrm{PbSO}_{4}$ has been found on sulfuric acid-treated galena. Baryte, however, comprises $1.2 \%$ of the total orebody [9] and represents the optimal vehicle for an engineered CDR solution. Evidence exists from LA-ICP-MS data of naturally occurring lead uptake in baryte, which increases greatly in the sulfuric acid leach bath [38]. Figure 18 shows nanoSIMS images of baryte exhibiting (CDR-induced?) porosity correlating with ${ }^{206} \mathrm{~Pb},{ }^{210} \mathrm{~Pb}$, and ${ }^{226} \mathrm{Ra}$ concentrations. If CDR is already taking place in the leach tank to some extent, optimizing the process for maximum $\mathrm{Pb}$ and $\mathrm{Ra}$ removal becomes an achievable goal.

Results from these experiments set the stage for further investigation of radionuclide uptake during minerals processing, especially during acid leaching. At Olympic Dam, the primary RNs of concern during processing are ${ }^{226} \mathrm{Ra},{ }^{210} \mathrm{~Pb}$, and ${ }^{210} \mathrm{Po}$. These elements, along with $\mathrm{Sr}$ and $\mathrm{Ba}$, represent the entire suite of acid-insoluble sulfates. Considering the commonplace use of sulfuric acid for leaching, understanding the behavior of these sulfates is paramount to controlling their deportment. The evidence provided here enhances our knowledge of this family of micro- to nanoscale chemical interactions and will not only aid in determining where RNs reside during each stage of processing but will also establish the foundation for a plan targeting their removal.

\section{Conclusions}

Results suggest that three distinct mechanisms are involved: overgrowth; diffusion; and CDR. Overgrowth is common for both $\mathrm{Pb}$ - and $\mathrm{SrSO}_{4}$ on barytes (in low $\mathrm{pH}$, high sulfate solutions), with little evidence that significant amounts of $\mathrm{Pb}$ or $\mathrm{Sr}$ are incorporated into the baryte structure. Celestite hosts only small amounts of $\mathrm{Ba}$ or $\mathrm{Pb}$ (generally up to $1 \mathrm{wt} \%$ ) through porosity-driven diffusion, though very thin overgrowth zones or spots appear sporadically in both cases. Anglesite is readily dissolved and replaced through CDR at low $\mathrm{pH}$ conditions, although the effect is somewhat dampened by the presence of excess sulfate. Strontium replacement of $\mathrm{Pb}$ averages $\sim 75 \%$ (m.b.) in acid chloride solution but is reduced 
to $10 \mathrm{wt} \%$ in neutral chloride or acid sulfate solutions. Barium substitution through CDR increases in highsulfate conditions, but never exceeds 4 wt\%. Diffusion of both $\mathrm{Ba}$ and $\mathrm{Sr}$ into anglesite does occur along crystallographic axes, but only at very low concentrations.

\section{Abbreviations}

amu: atomic mass units; BSE: back scatter electron; CDR: coupled dissolution/reprecipitation; CIR: crystal ionic radius; CMCA: Centre for Microscopy, Characterisation, and Analysis; EDS: electron dispersive spectroscopy; FEG: field emission gun; IOCG-U: iron oxide-copper-gold-uranium; LA-ICP-MS: laser ablation inductively coupled plasma mass spectrometry; m.b.: metals basis; nanoSIMS: nanoscale secondary ion mass spectrometry; ppm: parts per million; ppq: parts per quadrillion; ppt: parts per trillion; RN: radionuclide; RO: reverse osmosis; SEM: scanning electron microscopy.

\section{List of symbols}

B: geometric factor; $J(x)$ : nucleation rate; $\mathrm{k}$ : Boltzmann's constant; $\mathrm{K}_{\mathrm{sp}}$ : solubility product; $\mathrm{S}(\mathrm{x})$ : supersaturation function; $\mathrm{T}$ : temperature (in Kelvin); $\Gamma(\mathrm{x})$ : preexponential factor; $\Sigma(\mathrm{x})$ : interfacial free energy; $\Omega(\mathrm{x})$ : molecular volume.

\section{Acknowledgements}

The authors thank Ken Neubauer and Dr. Alec Walsh for additional analytical support, Dr. Jon Tyler for laboratory access, and Dr. Ruth Shaw and Prof. Stephen Grano for project management support. We would also like to thank the editors and reviewers for their valuable insight and suggestions, which helped make this a stronger and clearer manuscript.

\section{Authors' contributions}

MR, SG, and PG performed the work presented here. MR processed results and made interpretations, supervised by NJC. KE supplied sample material and provided extensive advice. MR wrote the manuscript assisted by NJC and other co-authors. All authors read and approved the final manuscript.

\section{Funding}

This is a contribution to the ARC Research Hub for Australian Copper-Uranium (Grant IH130200033), co-supported by BHP Olympic Dam.

\section{Availability of data and materials}

The data presented above remain the property of, and will only be dispersed at the discretion of, $\mathrm{BHP}$.

\section{Competing interests}

The authors declare that they have no competing interests.

\section{Author details}

1 School of Chemical Engineering, The University of Adelaide, Adelaide, SA 5005, Australia. ${ }^{2}$ Centre for Microscopy, Characterisation, and Analysis, The University of Western Australia, 35 Stirling Highway, Crawley, WA 6009, Australia. ${ }^{3}$ BHP Olympic Dam, 55 Grenfell St., Adelaide, SA 5000, Australia.

${ }^{4}$ Adelaide Microscopy, The University of Adelaide, Adelaide, SA 5005, Australia.

Received: 3 March 2019 Accepted: 26 August 2019

Published online: 05 September 2019

\section{References}

1. Anderson JG, Larson MA, Doraiswamy LK (1998) Microphase-assisted "autocatalysis" in a solid-liquid reaction with a precipitating product-II. Experimental. Chem Eng Sci. 53(13):2459-2468

2. Blazek MC (1979) Classification of pseudomorphs. Rocks Miner. 54(5):194-197

3. Brown PL, Ekberg C, Ramebäck H, Hedström H, Matyskin A. Solubility of radium and strontium sulfate across the temperature range of 0 to 300 C. In: Merkel BJ, Arab A, editors. Uranium-past and future challengesproceedings of the 7 th international conference on uranium mining and hydrogeology. Springer, Cham; 2015. pp 553-564
4. Christy AG, Putnis A (1993) The kinetics of barite dissolution and precipitation in water and sodium chloride brines at 44-85 C. Geochim Cosmochim Acta 57(10):2161-2168

5. Collins AG, Davis JW (1971) Solubility of barium and strontium sulfates in strong electrolyte solutions. Environ Sci Technol 5(10):1039-1043

6. Cook NJ, Ciobanu CL, George L, Zhu ZY, Wade B, Ehrig K (2016) Trace element analysis of minerals in magmatic-hydrothermal ores by laser ablation inductively-coupled plasma mass spectrometry: approaches and opportunities. Minerals 6(4):111

7. Dai Z, Kan AT, Shi W, Yan F, Zhang F, Bhandari N, Ruan G, Zhang Z, Liu Y, Alsaiari HA, Lu YT (2017) Calcite and barite solubility measurements in mixed electrolyte solutions and development of a comprehensive model for water-mineral-gas equilibrium of the $\mathrm{Na}-\mathrm{K}-\mathrm{Mg}-\mathrm{Ca}-\mathrm{Ba}-\mathrm{Sr}-\mathrm{Cl}-\mathrm{SO}_{4}-\mathrm{CO}_{3}$ $\mathrm{HCO}_{3}-\mathrm{CO}_{2}$ (aq) $-\mathrm{H}_{2} \mathrm{O}$ system up to $250{ }^{\circ} \mathrm{C}$ and 1500 bar. Ind Eng Chem Res 56(23):6548-6561

8. Dyar MD, Gunter ME, Tasa D (2008) Mineralogy and optical mineralogy. Mineral Soc Am, Chantilly

9. Ehrig K, MCPhie J, Kamenetsky VS. Geology and mineralogical zonation of the Olympic Dam iron oxide Cu-U-Au-Ag deposit, South Australia. In: Hedenquist JW, Harris M, Camus F, editors. Geology and genesis of major copper deposits and districts of the world, a tribute to Richard Sillitoe. Society of Economic Geologists Special Publication 16, Littleton, USA: 2012. pp 237-267

10. Fenter P, Sturchio NC (2004) Mineral-water interfacial structures revealed by synchrotron X-ray scattering. Prog Surf Sci 77(5-8):171-258

11. Figgins PE (1961) The radiochemistry of polonium. Mound Lab, Miamisburg

12. Haynes WM (2014) CRC Handbook of chemistry and physics. CRC Press, Baco Raton

13. Henisch HK (1996) Crystal growth in gels. Courier Corporation, North Chelmsford

14. Ilyas S, Srivastava RR, llyas N (2020) Biosorption of strontium from aqueous solutions. In: Pathak P, Gupta DK (eds) Strontium contamination in the environment. The handbook of environmental chemistry, 88th edn. Springer Nature, Berlin, pp 65-83

15. Kerisit S, Liu C (2009) Molecular simulations of water and ion diffusion in nanosized mineral fractures. Environ Sci Technol 43(3):777-782

16. Krumgalz BS (2018) Temperature dependence of mineral solubility in water. Part 3. Alkaline and alkaline earth sulfates. J Phys Chem Ref Data 47(2):023101

17. Lehman TA, Everett WW (1982) Solubility of lead sulfate in water and in sodium sulfate solutions: an experiment in atomic absorption spectrophotometry. J Chem Educ 59(9):797

18. Linke WF, Seidell A (1965) Solubilities, inorganic and metal-organic compounds, K-Z: a compilation of solubility data from the periodical literature. A revision and continuation of the compilation originated by Atherton Seidell. American Chemical Society, Washington

19. Longerich HP, Jackson SE, Günther D (1996) Inter-laboratory note. Laser ablation inductively coupled plasma mass spectrometric transient signal data acquisition and analyte concentration calculation. J Anal At Spectrom. 11(9):899-904

20. Lucchesi PJ, Whitney ED (1962) Solubility of strontium sulphate in water and aqueous solutions of hydrogen chloride, sodium chloride, sulphuric acid and sodium sulphate by the radiotracer method. J Appl Chem 12(6):277-279

21. Nguyen CK, Clark BN, Stone KR, Edwards MA (2011) Role of chloride, sulfate, and alkalinity on galvanic lead corrosion. Corrosion 67(6):065005

22. Patel AR, Bhat HL (1984) Gel growth of lead sulfate single crystals. In: Рост Кристаллоь/Rost Kristallov/growth of crystals. Springer, Boston. pp 122-125

23. Pina CM, Putnis A (2002) The kinetics of nucleation of solid solutions from aqueous solutions: a new model for calculating non-equilibrium distribution coefficients. Geochim Cosmochim Acta 66(2):185-192

24. Pina CM, Becker U, Risthaus P, Bosbach D, Putnis A (1998) Molecular-scale mechanisms of crystal growth in barite. Nature 395(6701):483-486

25. Poczatek C, Kaufman Z, Lechene C (2009) OpenMIMS ImageJ Plugin Guide. Harvard Medical School (Boston, Massachusetts, USA)

26. Putnis A (2002) Mineral replacement reactions: from macroscopic observations to microscopic mechanisms. Miner Mag 66(5):689-708

27. Putnis A (2009) Mineral replacement reactions. Rev Miner Geochem 70(1):87-124 
28. Putnis A, Mauthe $G$ (2001) The effect of pore size on cementation in porous rocks. Geofluids 1(1):37-41

29. Putnis A, Fernandez-Diaz L, Prieto M (1992) Experimentally produced oscillatory zoning in the $(\mathrm{Ba}, \mathrm{Sr}) \mathrm{SO}_{4}$ solid solution. Nature 358(6389):743-745

30. Putnis CV, Tsukamoto K, Nishimura Y (2005) Direct observations of pseudomorphism: compositional and textural evolution at a fluid-solid interface. Am Mineral 90:1909-1912

31. Raju K, Atkinson G (1988) Thermodynamics of" scale" mineral solubilities. 1. Barium sulfate (s) in water and aqueous sodium chloride. J Chem Eng Data 33(4):490-495

32. Raju K, Atkinson G (1989) Thermodynamics of" scale" mineral solubilities. 2. Strontium sulfate (s) in aqueous sodium chloride. J Chem Eng Data 34(3):361-364

33. Rollog M, Cook NJ, Guagliardo P, Ehrig K, Kilburn M (2019) In situ spatial distribution mapping of radionuclides in minerals by nanoSIMS. Geochem Explor Environ Anal 19:245-254. https://doi.org/10.1144/geoch em2018-038

34. Ruiz-Agudo E, Putnis CV, Putnis A (2014) Coupled dissolution and precipitation at mineral-fluid interfaces. Chem Geol 383:132-146

35. Sangwal K (1989) On the estimation of surface entropy factor, interfacial tension, dissolution enthalpy and metastable zone-width for substances crystallizing from solution. J Cryst Growth 97(2):393-405

36. Schindelin J, Arganda-Carreras I, Frise E, Kaynig V, Longair M, Pietzsch T, Preibisch S, Rueden C, Saalfeld S, Schmid B, Tinevez JY (2012) Fiji: an open-source platform for biological-image analysis. Nat Methods 9(7):676

37. Schindelin J, Rueden CT, Hiner MC, Eliceiri KW (2015) The ImageJ ecosystem: an open platform for biomedical image analysis. Mol Reprod Dev 82(7-8):518-529
38. Schmandt DS, Cook NJ, Ehrig K, Gilbert S, Wade BP, Rollog M, Ciobanu CL, Kamenetsky VS (2019) Uptake of trace elements by baryte during copper ore processing: a case study from Olympic Dam, South Australia. Miner Eng 135:83-94

39. Shannon RD (1976) Revised effective ionic radii and systematic studies of interatomic distances in halides and chalcogenides. Acta Crystallogr Sect A 32(5):751-767

40. Söhnel O (1982) Electrolyte crystal-aqueous solution interfacial tensions from crystallization data. J Cryst Growth 57(1):101-108

41. Steefel Cl, Lichtner PC (1998) Multicomponent reactive transport in discrete fractures: I. Controls on reaction front geometry. J Hydrol. 209(1-4):186-199

42. Steefel Cl, Lichtner PC (1998) Multicomponent reactive transport in discrete fractures: II: Infiltration of hyperalkaline groundwater at Maqarin, Jordan, a natural analogue site. J Hydrol 209(1-4):200-224

43. Srivastava RR, llyas S (2020) Strontium extraction from the Geo-environment. In: Pathak P, Gupta DK (eds) Strontium contamination in the environment. The handbook of environmental chemistry, 88th edn. Springer Nature, Berlin, pp 43-63

44. Zhang T, Gregory K, Hammack RW, Vidic RD (2014) Co-precipitation of radium with barium and strontium sulfate and its impact on the fate of radium during treatment of produced water from unconventional gas extraction. Environ Sci Technol 48(8):4596-4603

\section{Publisher's Note}

Springer Nature remains neutral with regard to jurisdictional claims in published maps and institutional affiliations.
Ready to submit your research? Choose BMC and benefit from:

- fast, convenient online submission

- thorough peer review by experienced researchers in your field

- rapid publication on acceptance

- support for research data, including large and complex data types

- gold Open Access which fosters wider collaboration and increased citations

- maximum visibility for your research: over 100M website views per year

At BMC, research is always in progress.

Learn more biomedcentral.com/submissions 